\title{
IMPLEMENTING A NOVEL CYCLIC CO2 FLOOD IN PALEOZOIC REEFS
}

TYPE OF REPORT: SEMI-ANNUAL

REPORTING PERIOD START DATE: JULY 1, 2003

REPORTING PERIOD END DATE: DECEMBER 31, 2003

PRINCIPAL AUTHORS:

JAMES R. WOOD, MICHIGAN TECHNOLOGICAL UNIVERSITY, HOUGHTON, MI W. QUINLAN, JORDAN EXPLORATION COMPANY LLC, TRAVERSE CITY, MI. A. WYLIE, MICHIGAN TECHNOLOGICAL UNIVERSITY, HOUGHTON, MI

DATE REPORT WAS ISSUED: JANUARY, 2004

DOE AWARD NUMBER: DE-FC26-02BC15441

NAME AND ADDRESS OF SUBMITTING ORGANIZATION:

MICHIGAN TECHNOLOGICAL UNIVERSITY

1400 TOWNSEND DRIVE

HOUGHTON, MI. 49931 


\section{DISCLAIMER}

This report was prepared as an account of work sponsored by an agency of the United States Government. Neither the United States Government nor any agency thereof, nor any of their employees, makes any warranty, express or implied, or assumes any legal liability or responsibility for the accuracy, completeness, or usefulness of any information, apparatus, product or process disclosed, or represents that its use would not infringe on any privately owned rights. Reference herein to any specific commercial product, process, or service by trade name, trademark, manufacturer, or otherwise, does not necessarily constitute or imply its endorsement, recommendation or favoring by the United States Government nor any agency thereof. The views and opinions of authors expressed herein do not necessarily state or reflect those of the United States Government or any agency thereof. 


\begin{abstract}
Recycled CO2 will be used in this demonstration project to produce bypassed oil from the Silurian Dover 35 pinnacle reef (Otsego County) in the Michigan Basin. Contract negotiations by our industry partner to gain access to the $\mathrm{CO} 2$ supply have been completed and the State of Michigan has issued an order to allow operation of the project. Injection of CO2 is scheduled to begin in February, 2004. Subsurface characterization is being completed using well log tomography animations and 3D visualizations to map facies distributions and reservoir properties in two reefs, the Belle River Mills and Chester 18 Fields. The Belle River Mills and Chester18 fields are being used as type-fields because they have excellent log and/or core data coverage. Amplitude slicing of the normalized gamma ray and core permeability and core porosity curves is showing trends that indicate significant heterogeneity and compartmentalization in these reservoirs associated with the original depositional fabric of the rocks.

Digital and hard copy data continues to be compiled for the Niagaran reefs in the Michigan Basin. Technology transfer took place through technical presentations regarding visualization of the heterogeneity of the Niagaran reefs. An oral presentation was given at the AAPG Eastern Section Meeting and a booth at the same meeting was used to meet one-on-one with operators.
\end{abstract}




\section{TABLE OF CONTENTS}

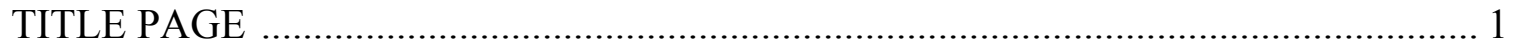

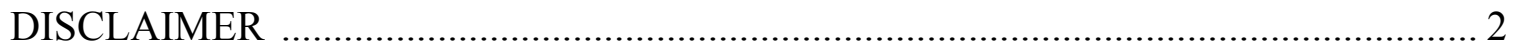

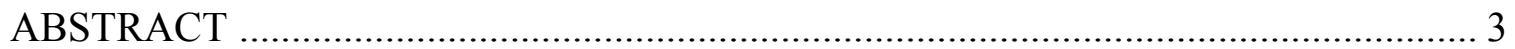

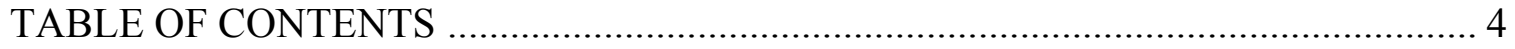

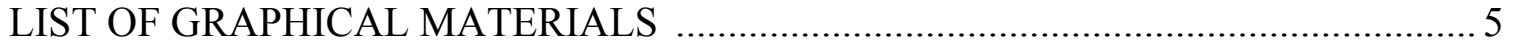

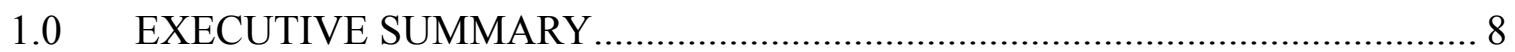

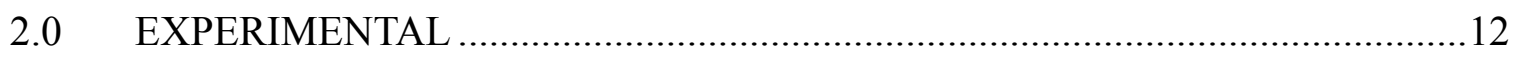

$2.1 \quad$ Log Data

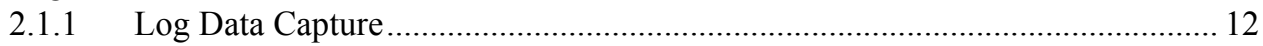

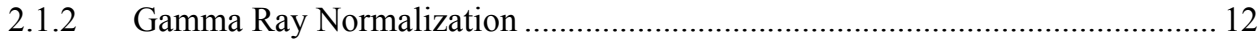

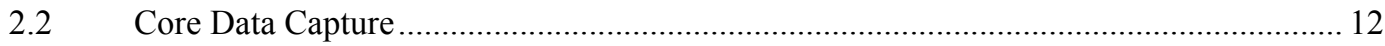

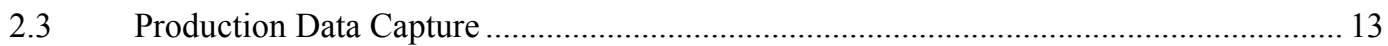

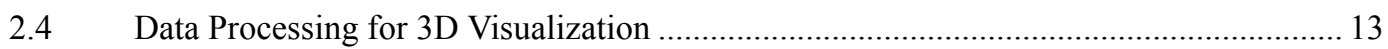

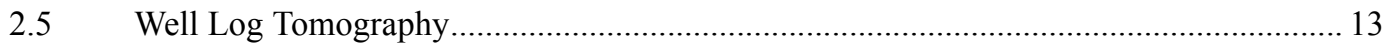

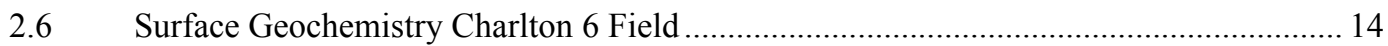

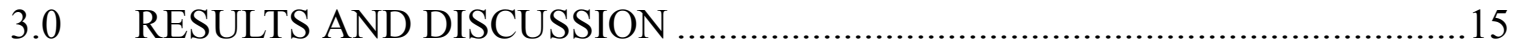

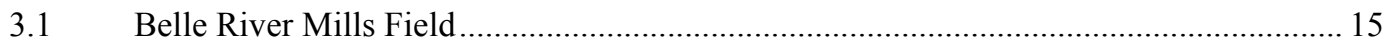

3.1.1 Gamma Ray Log Curve Statistics, Belle River Mills Field, St. Clair County, Michigan15

3.1.2 Core Permeability and Core Porosity Statistics, Belle River Mills Field, St. Clair County, Michigan16

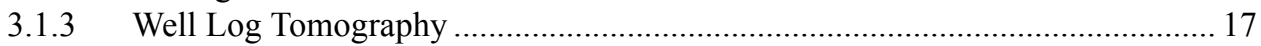

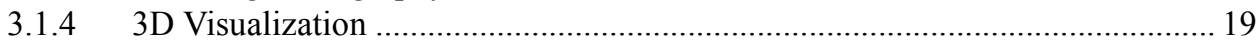

3.2 Log Curve Amplitude Slicing in the Chester 18 Field, Otsego County, Michigan............ 20

3.3 Surface Geochemistry in the Charlton 6 Field, Otsego County, Michigan......................... 21

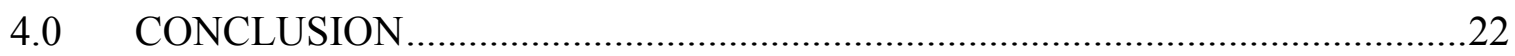

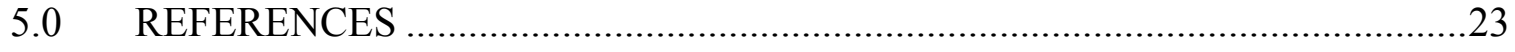

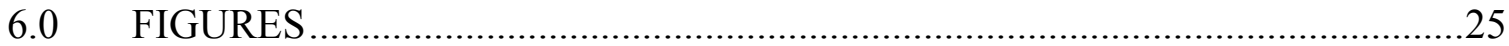




\section{LIST OF GRAPHICAL MATERIALS}

Figure 1. (a) Location of Dover 35 Field in Otsego County, Michigan. (b) Location map for Dover 35 demonstration project area showing CO2 supply and distribution pipelines, old demonstration site, Charlton 6 and new demonstration site, Dover 35 (green outline).

Figure 2. (a) Devonian through Ordovician stratigraphic column for the Michigan Basin and (b) typical detailed stratigraphic column for a Niagaran reef and vicinity (Gill, 1977).

Figure 3. Location map for Dover 35 Field area. The 4 wells in the field are shown inside the black outline. One of these wells will be used as the CO2 injector and 2 or 3 of the wells will be used as producers in the demonstration project. Data posted around the well spots is operator, well name, well number, year drilled, KB, permit number, total depth, top Niagaran Brown measured and subsea depths, and top Niagaran Gray measured depth; small well spots are shallow Antrim wells. Section 35 is one square mile. North is towards the top of the map.

Figure 4. Map of Niagaran rocks in the Michigan basin showing three depositional trends and location of Belle River Mills and Chester 18 type Niagaran Reef Fields (Gill, 1977).

Figure 5. Summary of Log Curve Amplitude Slicing or Well Log Tomography technique showing bottom-up slicing from base of a Niagaran Reef.

Figure 6. (a) Belle River Mills top boundstone structure contour map (Gill, 1977) showing field extents. (b) Belle River Mills central area top of reef (stromatolite) structure contour map from Rockworks2002. Maximum reef height is 400 feet above the non-reef Brown Niagaran. The contour interval is 50 feet. Red circles indicate cored wells, blue circles indicate reef wells, and green circles indicate reef rubble wells.

Figure 7. (a) Gamma ray curve cross section from reef to non-reef for the Belle River Mills Field (location shown on Figure 6b). Representative log curve slices are flattened using the base of the reef and sliced horizontally within the reef or from reef to non-reef salina. Depth scale and gamma ray scales are shown in figure. (b) Generalized facies of Niagaran Reef. Salina evaporite and carbonate units encase and seal the reef. Vertical exaggeration is $2 \mathrm{X}$ (after Gill, 1977).

Figure 8. Gamma ray curve amplitude ranges and statistics for reef and non-reef facies based upon correlations of Gill (1977).

Figure 9. Core permeability versus core porosity by rock type (after Gill, 1977) in the Belle River Mills reef; "n" represents number of samples for each rock type.

Figure 10. Histograms of core porosity and core permeability by rock type in the Belle River Mills Field. Number of samples in histogram is shown in parenthesis below averages. Numbers in brackets are number of samples of permeability higher than 100 millidarcies or in the range 100-7000 millidarcies.

Figure 11a. Cumulative percent plot of reef core permeability for all rock types in the Belle River Mills Field, St. Clair County, Michigan. 
Figure 11b. Cumulative percent plot of reef core permeability by four rock types in the Belle River Mills Field, St. Clair County, Michigan. Permeability measurements greater than $30 \mathrm{md}$ were reset to $30 \mathrm{md}$ to enable visualization of permeability trends in the $3 \mathrm{D}$ model.

Figure 12a. Cumulative percent plot of reef core porosity for all rock types in the Belle River Mills Field, St. Clair County, Michigan.

Figure 12b. Cumulative percent plot of reef core porosity by four rock types in the Belle River Mills Field, St. Clair County, Michigan.

Figure 13. Log Curve Amplitude Slice number 175 from the core permeability slicing. Slice 175 is 175 feet above the base of the reef and is located in the boundstone. A zero permeability outline was used to constrain the gridding of each slice and to prevent gridding edge affects. Slice 175 is shown relative to the permeability curve and the general reef stratigraphy on the right. Large white dots are data control points on each slice and small white dots are other well locations.

Figure 14. Belle River Mills core permeability bottom-up amplitude slicing from reef base to midreef. The data range is from 0 to 30 millidarcies with values greater than 30 md reset to 30 . The contour interval for each slice is 4 millidarcies. Gray lines are section boundaries and gray numbers are section numbers. North is toward the top of the slices. Large white dots are data control points on each slice and small white dots are other well locations. Slice numbers or elevation in feet above the reef base are displayed in yellow below the vertical scale bar.

Figure 15. Belle River Mills core porosity bottom-up amplitude slicing from reef base to midreef. The data range is from 0 to 30 percent. The contour interval for each slice is $4 \%$. Gray lines are section boundaries and gray numbers are section numbers. North is toward the top of the slices. Large white dots are data control points on each slice and small white dots are other well locations. Slice numbers or elevation in feet above the reef base are displayed in yellow below the vertical scale bar.

Figure 16. Belle River Mills gamma ray bottom-up amplitude slicing from reef base to mid-reef. The data range is from 0 to 40 api units. The contour interval is 5 api units. All wells in the field have gamma ray curves through the reef. Gray lines are section boundaries and gray numbers are section numbers. North is toward the top of the slices. Large white dots are data control points on each slice and small white dots are other well locations. Slice numbers or elevation in feet above the reef base are displayed in yellow below the vertical scale bar.

Figure 17. Comparison of two key core permeability, core porosity, and gamma ray slices from the wackestone and boundstone in the Belle River Mills Field. Note the permeability and porosity amplitude trends are approximately equivalent to the trends observed in the gamma ray amplitudes. This is an important observation and is significant in that it means we may be able to use log curve amplitude slicing of the gamma ray curves only to visualize the approximate distribution of permeability and porosity in reefs without core data (most Niagaran Reef wells have at least a gamma ray log curve) by utilizing the data from these type reefs.

Figure 18. Belle River Mills “Glass Reef”, showing permeability voxels ( $>25 \mathrm{md}$, best quality reservoir), stratigraphy, cored intervals, and top reef structure surface. The color scale on the left is core permeability in millidarcies from 0 to 30 . Vertical exaggeration is $10 \mathrm{X}$. View is looking northwest, 30 degrees above horizontal. Inset is same display with no vertical exaggeration and 
top of reef structural contours and landgrid overlays. Voxel resolution is 115 feet in the $x-$ and $y-$ directions and six feet in the z-direction.

Figure 19. Belle River Mills “Glass Reef” presentation, showing permeability voxels 25 md and greater (yellow and orange), stratigraphy (blues), cored intervals (red), and transparent top reef structure surface. The color scale on the left is core permeability in millidarcies from 0 to 30 . View is looking directly west. The cyan blue line in middle of reef is the deviated well drilled in 2000 (refer to Figure 6b). Vertical exaggeration is 10X. Voxel resolution is 115 feet in the $\mathrm{X}$ - and $\mathrm{y}$-directions and six feet in the z-direction.

Figure 20. Belle River Mills 3D reef presentation, showing permeability voxels $20 \mathrm{md}$ and greater (yellow and orange), original perforated intervals (purple), and transparent crestal reef structure surface. The color scale on the left is core permeability in millidarcies from 0 to 30 . View is looking directly west. Note the great thickness of perforations relative to the best permeability trends in the reservoir. The location of the perforations relative to the best permeability could impact primary, secondary, and enhanced recovery efforts as well as gas storage operations. Vertical exaggeration is 10X. Voxel resolution is 115 feet in the $\mathrm{x}$ - and $\mathrm{y}$-directions and six feet in the z-direction.

Figure 21. Belle River Mills 3D reef presentation, showing permeability voxels $25 \mathrm{md}$ and greater (green), porosity voxels $13 \%$ and greater (red), original perforated intervals (purple), and transparent crestal reef structure surface. View is looking directly west. Note the location of the best permeability and porosity in relation to the perforated intervals. The best permeability is not necessarily coincident with the best porosity.

Figure 22. Belle River Mills 3D reef presentation, showing permeability voxels 25 md and greater (green), porosity voxels $13 \%$ and greater (red), rock types (blues and green), and transparent crestal reef structure surface. View is looking northwest. The best permeability and porosity is located in the upper wackestone and lower boundstone rock types. The stromatolite rock type generally has poor quality permeability and porosity. Storage and deliverability capacities of this gas storage reservoir could be optimized using this type of $3 \mathrm{D}$ visualization analysis.

Figure 23. Structure map on the top of the Brown Niagaran (reservoir) for the Chester 18 Field, Otsego County, Michigan, 4 miles southwest of Dover 35 demonstration project (refer to Figure $1 b)$.

Figure 24. One gamma ray amplitude slice through Chester 18 Field (214 feet from reef base) displaying trends in the amplitude of the gamma ray curve. Slice contours indicate possibility of two depositional centers or two reefs that coalesced to form the Chester 18 reservoir. Pressure performance from the reservoir also indicates the possibility of two coalesced reefs.

Figure 25. Microbial contour map of Charlton 6 area, Otsego County, Michigan, showing microbial concentrations from surface geochemical sampling. 


\subsection{EXECUTIVE SUMMARY}

\section{Goals and Results}

The primary goals of this project are to:

1. Demonstrate through a field trial that significant quantities of by-passed hydrocarbons can be recovered from pinnacle reefs using a novel $\mathrm{CO} 2$ cycling technology. The $\mathrm{CO} 2$ will come from nearby Antrim gas processing facilities resulting in the added benefit of the $\mathrm{CO} 2$ being sequestered rather than vented to the atmosphere.

2. Use log-curve tomography to develop a 3D digital model of a pinnacle reef.

3. Inventory the Michigan Basin for abandoned or shut-in reefs that are suitable candidates for similar recovery efforts. Compile pertinent engineering and geological characteristics in digital format.

4. Pass the results, economics, and data obtained from the demonstration project along to small independent producers via an aggressive technology transfer program.

\section{Field Demonstration}

The field demonstration project was shifted three miles to the west to the Dover 35 Niagaran Field from the Charlton 6 Field based upon $\mathrm{CO} 2$ availability and flooding schedules (Figures 1 and 2). The change in the demonstration well site has been approved by the DOE. Contract negotiations between our industry partner (Jordan Exploration Company, LLC) and the CO2 supplier (Core Energy, LLC) have reached completion. The State of Michigan has issued an order granting our industry partner's application to begin the project. We expect to begin demonstration well operations and start injecting $\mathrm{CO} 2$ in the first quarter of 2004.

Figure 3 is a detailed location map for the Dover 35 Field area. The Salling Hansen \#1-35 (Michigan permit number 29236), the Salling-Hansen \#4-35A (Michigan permit number 29995), the Pomerzynski \#5-35 (Michigan permit number 37324), and the Pomerzynski \#2-35 (Michigan permit number 29374) will be used as producing and/or the CO2 injection wells for the demonstration project. Our industry partner is currently determining which of these for wells will be used as the injection well.

\section{Analogs}

Significant progress has been made modeling two Niagaran reef reservoirs. The Belle River Mills Field located in the southern reef trend in St. Clair County, Michigan was selected as an analog to Dover 35 because it has excellent well log coverage and core coverage, and rock descriptions of the core have been published (Figure 4); it is also a gas storage reservoir. The Chester 18 Field was chosen as the second analog because it is located in the northern reef trend in Otsego County approximately four miles to the southwest of the Dover 35 Field demonstration site, has excellent 
log curve coverage, and has been waterflooded (Figures 1 and 4). Log curve amplitude slicing animations of the gamma ray curves in these two fields have been created and all the log curves in the fields have been digitized. The core analysis data from the 34 cored wells in the Belle River Mills Field has been located and entered into a digital database. Amplitude slices and 3D visualizations have been created of the core porosity and core permeability distribution in the Belle River Mills reef. The logs for the Dover 35 and Charlton 6 Fields have been digitized and other logs for wells in the vicinity of the fields are presently being digitized. Approximately 100 digital well log curve files (LAS files) were obtained from a Michigan operator for the northern reef trend. These digital files are being edited and quality controlled and along with the digital well log data captured for this demonstration project will form the basis for a digital Michigan Basin Niagaran reef well log database.

\section{Data Compilation}

Engineering data is currently being compiled for Niagaran reefs in the Michigan Basin. The Michigan Department of Natural Resources production database from January 1982 through July 2003 has been manipulated to create a digital report of the production for all Niagaran Fields. A complete set of the paper copy Michigan Department of Natural Resources production reports (1932 through 1984) has been obtained to use to begin the process of capturing historical Niagaran production data in our production database. A separate digital database has been created from the Michigan Tech well databases showing wells that were cored in the Niagaran in the Michigan Basin. A similar spreadsheet listing wells with Niagaran cores in the Michigan Basin is located on the Michigan Basin Core Research Laboratory web site at Western Michigan University [http:// www.wmich.edu/geology/corelab/corelab.htm]. The Michigan Department of Natural Resources historical paper copy pressure reports for the Niagaran Reef trend have been obtained and initial (virgin) reservoir pressure data from these reports is being entered into a pressure database.

\section{New Findings}

One key new finding has emerged from our 3D visualization work during the reporting period. It appears that the best permeability and porosity in the Niagaran Reefs are not necessarily coincident. In other words, high permeability does not always indicate high porosity nor does low permeability always indicate low porosity. It appears that the distribution of permeability and porosity in the reefs is controlled by the original depositional fabric of the carbonate rocks (i.e., vuggy, pinpoint, moldic fabrics, among others) and that subsequent diagenesis has only partially modified this original depositional and rock property fabric (i.e., dolomitization of the original limestones has not completely removed this original fabric).

A second key new finding is that the distribution of the permeability and porosity in the Belle River Mills reef determined from the core data corresponds with the trends observed in the $\log$ curve amplitude slicing of the normalized gamma ray log curves. This is an important observation and is significant because it means we may be able to use log curve amplitude slicing of the $\log$ curves as an indicator of the distribution of permeability and porosity in reefs without core data (most Niagaran Reef wells have at least a gamma ray and porosity log curve). By scaling the areal distribution of this relationship (probably calibrated with additional analogs) we may be able 
to predict the likely distribution of the permeability and porosity in the Dover 35 Field among others.

A third key finding is that high-resolution images of the larger multi-well Niagaran Fields can be obtained using well log tomography. Tomography of the Belle River Mills and Chester 18 Fields shows that these fields are really composed of five and two, respectively, individual reefs (or carbonate sediment production centers) that have coalesced to form what has been called a single reef field. Reservoir engineering data from previous studies by the operator in the case of the Chester 18 Field supports the interpretation of two distinct reefs or pressure/production compartments. The gamma ray, core porosity, and core permeability amplitude slicing at Belle River Mills show five areal subdivisions to the field (refer to Figures in Discussion and Results section).

\section{Lessons Learned}

We have learned that there is no substitute for capturing and visualizing the various types of Niagaran reef reservoir data. 3D visualization and well log tomography of the core permeability, core porosity, and gamma ray log data have revealed new observations about the distribution of important reservoir properties in the reefs that impact producibility and economics for these reservoirs.

We have also learned that flexibility must be maintained by all parties to optimize the timelines for flooding the best and most accessible reefs first (e.g., changing of demonstration project to Dover 35 from Charlton 6) to insure optimum economics and recovery. We also learned that negotiations for a $\mathrm{CO} 2$ supply contract using waste gas from Antrim processing facilities can become very involved from a legal and contract perspective and take longer than expected.

\section{Applications}

The results of the 3D visualizations and well log tomography of the Belle River Mills and Chester 18 type fields will be applied using well data to the Dover 35 field and to several other mediumsize Niagaran fields near the demonstration site.

Well log tomography is showing that the reservoir properties of the Niagaran reefs in the Michigan Basin vary both horizontally and vertically. These variations in permeability, porosity, and connectivity of the reservoir rock must be considered to insure that enhanced recovery operations including CO2 injection, horizontal well placement, and gas storage facilities are designed appropriately. It appears likely that previous interpretations of reservoir and production engineering data suggesting that many Niagaran reefs deplete uniformly are incorrect.

Reefs in the Devonian Traverse Group in the Michigan Basin and in many stratigraphic intervals in other U.S. basins are logical targets for application of 3D visualization and well log tomography to assist in the determination of the viability of secondary or tertiary recovery projects and $\mathrm{CO} 2$ sequestration. Our recent results in combination with the technical literature on world-wide reefs suggest that most reef reservoirs may have undrained reservoir compartments. 


\section{Future Work}

The demonstration injection well when selected will be plugged back to a shallower position in the reef and $\mathrm{CO} 2$ injection will begin to re-pressurize the reef. The demonstration production wells will produce oil and eventually oil and $\mathrm{CO} 2$ that will be recycled. Surface facilities for handling the $\mathrm{CO} 2$ supply, $\mathrm{CO} 2$ injection, and the produced hydrocarbons and $\mathrm{CO} 2$ will be constructed and placed into operation in the first quarter of 2004.

The 3D visualization and well log tomography techniques applied to our type-reef fields will be applied to the Dover 35 reef and vicinity during the next six month project period. Well, field, and reservoir data will continue to be gathered for other Niagaran reefs in the Michigan Basin to identify likely candidates and the potential for future $\mathrm{CO} 2$ injection and sequestration projects in the Niagaran reefs.

\section{Technology Transfer}

First six months:

A technical paper on the preliminary slicing of the gamma ray log curves for Belle River Mills and Chester 18 Fields was presented at the Eastern Section Meeting of the American Association of Petroleum Geologist's meeting in Champaign, IL. A log curve amplitude slicing presentation was made to the Northern Section of the Society of Petroleum Engineers at a meeting in Traverse City, MI. A booth was set up at the Midwest PTTC horizontal well conference in Mt. Pleasant, MI in March, 2003 to show operators in the Basin log curve slicing animations and maps of the gamma ray curves for the Belle River Mills and Chester 18 Fields. A technical paper on the well log tomography or log curve amplitude slicing technique was published in the April 2003 issue of the Bulletin of the American Association of Petroleum Geologists.

\section{$\underline{\text { Second six months: }}$}

A technical paper on the results of the $3 \mathrm{D}$ visualization and well log tomography for the Belle River Mills field was presented at the Eastern Section Meeting of the American Association of Petroleum Geologist's meeting in Pittsburgh, PA in September, 2003. A booth was set up at the AAPG meeting with computer hardware to show live animations and visualizations of the Belle River Mills reef to basin operators and technical personnel. A seminar was presented at Western Michigan University on well log tomography with examples from the Michigan Basin, including the Niagaran reefs. Live 3D visualization demonstrations of the Belle River Mills reef were shown to basin operators during the PTTC core workshop in Mt. Pleasant, MI in October, 2003. An invited presentation was made at the U. S. Geological Survey in Reston, VA in December, 2003 to show well log tomography and 3D visualization of the Belle River Mills reef. A presentation was made at the SPE CO2 Conference in Midland, TX in December, 2003 by one of our industry partners regarding the Dover 35 field demonstration.

Results and presentations from a portion of this technology transfer are available on the internet at http://www.geo.mtu.edu/ aswylie/indxhtml.htm while our main subsurface visualization web page (http://www.geo.mtu.edu/svl/) is being updated and expanded. 


\subsection{EXPERIMENTAL}

\subsection{Log Data}

\subsubsection{Log Data Capture}

Paper copies of the well logs for the Dover 35, Charlton 6, Belle River Mills and Chester 18 Fields and surrounding area were obtained from the files at Michigan Tech and scanned to create tagged image format (tif) digital images using the commercial Neuralog software and a 36-inch scanner. Neuralog software was used to digitize the gamma ray and/or transit time (sonic), bulk density, neutron, and resistivity log curves for each well; the resistivity curves were not captured for Belle River Mills due to their vintage and low vertical resolution. Log ASCII Standard 2.0 (LAS) files were output from the Neuralog software to use in log curve amplitude slicing and cross sections.

\subsubsection{Gamma Ray Normalization}

We have found that well log curves have to be normalized to eliminate variability due to $\log$ tool types, log tool sensitivity, or log calibration between wells over time (see Neinast and Knox, 1974; Shier, 1997; Collins, 1998). Histograms and mean and standard deviations were computed for each of the 60 gamma ray curves using the bottom 100 feet of the Salina B salt (all wells penetrate this unit) to check for tool calibration errors, operator and tool vintage errors, and to low side normalize the gamma ray curves. Log curves from a group of wells were then selected (qualitatively) where the means and standard deviations for this interval were very similar to create a type histogram to use to normalize the remaining log curves that were deemed in error or in need or correction. Approximately 10 wells needed to have the gamma ray curves shifted. One well could not be corrected and was removed from the data set. A high-side gamma ray normalization was attempted using the Salina $\mathrm{C}$ Shale but was abandoned as unnecessary after reviewing preliminary statistics.

\subsection{Core Data Capture}

Paper copies of core analysis reports for the 34 cored wells in the Belle River Mills field were obtained from the Western Michigan University Core Repository through an exhaustive search of their files. Most of the core was analyzed using the whole core method but some plugs were utilized especially through broken core intervals. A spreadsheet was then created for each and the permeability, permeability at 90 degrees, porosity, water and oil saturation, and grain density (where available) measurements were entered into the spreadsheet. A one-foot sample increment was used for the core data and samples at tenths of feet were moved to the nearest even depth increment without losing samples. The null value (-999.2500) was used to denote missing samples or samples that were not analyzed. 7000 millidarcies (md) was the maximum permeability due to equipment measurement limits; $0.01 \mathrm{md}$ was used for all permeability measurements reported as less than $0.01 \mathrm{md}$. Trace oil saturation amounts (tr) in the original core report were assigned a value of 0.1 for the oil saturation. The core data were then converted to LAS files for 
use with cross sections and loaded to an Access database for well log tomography and data preparation for $3 \mathrm{D}$ visualization.

\subsection{Production Data Capture}

Digital monthly production data records from January 1982 through June 2003 were obtained from the Michigan Department of Natural Resources in a series of MS Access data files and then recombined into one composite MS Access database. This database contains field names and monthly oil, gas, natural gas liquids, and water production volumes among other data elements. These data can be used to create monthly decline plots for wells, production units, and fields. If the field went on line post January 1982 these data can be summed to determine cumulative production for the field for the period January 1982 through June 2003.

Historical monthly production records prior to January 1982 are not available in digital format from the State of Michigan at this time. Therefore, hardcopy annual reports from 1932 through 1984 were obtained with annual production data. We are beginning the process of entering the annual production from the hardcopy reports into our digital production database. This will enable us to create historical decline plots for Niagaran fields to use to analyze the performance of individual wells and groups of reservoirs. At this time, cumulative production can be taken from the final hardcopy report (1984) and in combination with the digital data records can be used to determine field level cumulatives.

\subsection{Data Processing for 3D Visualization}

In an effort to keep the cost of 3D visualization low, we decided to use the Rockware suite of software. Specifically, Rockworks2002 is capable of excellent 3D manipulation, visualization, and animations and is low cost at around $\$ 500$ (http://www.rockware.com/). The key step with the program is the data preparation or data processing to place the various types of data (i.e., logs, tops, locations, etc.) into the required Rockworks formats for loading into the program. A routine has been developed whereby the well and log data is first manipulated in an MS Access database and then used to populate the Rockworks2002 spreadsheet loader; however, when file length exceeds spreadsheet limits a series of ASCII text files must be used to load the data into the program. Drawbacks to the program are that all data must be reloaded each time new data is added to a project and the 3D visualization module of the program performs slowly when one foot sample increment log data is loaded for an entire project; a subset must be used to decrease processing and redraw times (Rockworks will release a new version in March 2004 that may correct some of these issues).

\subsection{Well Log Tomography}

Well log tomography also known as log curve amplitude slicing (Wylie and Huntoon, 2003; Wylie, 2002) is a form of tomography that utilizes the full vertical resolution of geophysical well log curves. Amplitude slices represent approximate time lines when the interval under analysis is bounded by unconformities or other chronostratigraphic surfaces and show the inferred distribution of lithofacies at the time of deposition. Computer animation allows visualization of changes 
in the distribution of lithofacies between successive slices or timelines. The distribution of other reservoir properties including porosity, permeability, and water saturation can also be visualized using the technique. The software used to create the tomographic animations includes MS Access, Golden Software Surfer, JASC Paintshop Pro Animator, and an in-house Visual Basic program.

In the case of the Niagaran reefs, only one chronostratigraphic surface is used (Figure 5). The base of the reef (or estimated base of the reef) in each well penetrating a reef is being used to establish one approximate time surface. Bottom-up slicing is then applied utilizing both reef and/ or non-reef well penetrations to visualize the distribution of any particular log curve amplitude or other regularly sampled (in depth) reservoir property such as core permeability or core porosity measurements.

\subsection{Surface Geochemistry Charlton 6 Field}

A geochemical sampling program was conducted over the Charlton 6 Field in October 2003 to test a new technique. Activated charcoal (AC) was buried 36 inches deep in glass vials with fine mesh screens over the tops of the jars and left in the ground for two weeks. The samples were then removed and analyzed using gas chromatography at MTU. The results from the 23 sample program at present are inconclusive: either the glass vials did not allow soil gases to reach the $\mathrm{AC}$, or the concentrations were uniformly below detection. Further tests will likely be conducted over Dover 35 using a modified collector (based on AC). 


\subsection{RESULTS AND DISCUSSION}

Extensive carbonate and evaporite deposition occurred during Middle-to-Late Silurian time when the Michigan Basin was located just south of the equator. Reconstructions by Scotese and others (1979) indicate the basin was located less than 30 degrees south. The general stratigraphic nomenclature for the Silurian in the Michigan basin is shown in Figure 2. During the middle Silurian Niagaran, the basin is typically divided into three depositional settings (Figure 4): 1) a shallow, basin-edge carbonate barrier reef or bank comprised of reef limestone, back-reef lagoonal deposits, patch reefs, and fore-reef lime mudstones and lime sandstones; 2) a gently sloping shelf, which includes the pinnacle reef belt and inter-reef micritic crinoidal limestones; and 3) a deep basin center with thinner deposits of dense, micritic, argillaceous limestones (Mantek, 1973; Gill, 1977, 1979; Friedman and Kopaska-Merkel, 1991; Leibold, 1992). The upper Silurian Salina units lap out against and overlie the Niagaran reefs and represent sediments deposited in a hypersaline environment during the initial stages of a major craton scale regression in the late Silurian (Sanford, 1969; Sloss, 1963, 1969, 1982a). The precise temporal relationship of the Salina and underlying Niagaran is unclear. Some workers postulate the two units are partly contemporaneous while others conclude Niagaran deposition ended before the deposition of the Salina (Mesolella et al., 1974; Kesling, 1974; Droste and Shaver, 1977; Huh et al., 1977; Gill, 1979; Sears and Lucia, 1980; Leibold, 1992). Gill (1977) presented a concise picture of the Niagaran and Salina stratigraphic relationships in the Belle River Mills Field (Figure2b) that can be used in most areas of the basin.

\subsection{Belle River Mills Field}

The Belle River Mills Field covers an area (Figure 6a and b) of 1760 acres and was discovered in 1961. The field produced over $21 \mathrm{BCF}$ of gas from 30 wells before conversion to a gas storage field in 1965. Gross distribution of reservoir facies and porosity zones in this Niagaran reef has been described based upon logs and cores (Gill, 1977). Belle River is currently operated by MichCon and has $47 \mathrm{BCF}$ of working gas capacity and $29 \mathrm{BCF}$ of base gas. All wells in the field area are vertical except for one horizontal well, the BRM 13HD-1 (permit number 53810, section 11, SENWSW), drilled in June 2000 (Figure 6b). This well was not used in the slicing because no well $\log$ was available.

\subsubsection{Gamma Ray Log Curve Statistics, Belle River Mills Field, St. Clair County, Michigan}

A reef-to-nonreef, stratigraphic cross section is shown in Figure 7a for Belle River Mills. The Lockport Dolomite or Gray Niagaran top defines the base of the reef, which is divided vertically into biohermal (wackestone), organic (boundstone), and supratidal (stromatolite) stages based upon Gill's core descriptions and formation tops (Figure 7b; Gill, 1977, 1979). The cross section shows the change in the gamma ray curve character from reef to non-reef and shows the lower Salina units pinching out against the reef flanks. The reef rubble conglomerate that typically rings a reef at its base is also shown.

Approximately 60 gamma ray curves from the Belle River Mills Field and surrounding area were scanned and digitized. The normalized gamma ray curve amplitudes were divided into intervals using Gill's (1977) subdivisions. Histograms were created of the gamma ray amplitudes for each 
of the intervals (Figure 8). Reef to non-reef slicing and use of non-reef gamma ray curve data was necessary to keep the gridding algorithm from creating incorrect contouring (spool ups) along the edges of the reef and map.

Another method used to prevent the gridding algorithm and color fill from reaching beyond the edge of the reef was to consider the Belle River Mills Field boundary as a series of pseudo-wells equal to zero gamma ray amplitude, zero permeability, or zero porosity. This provides a realistic limit for the gridding algorithm based upon the geology, likely reservoir properties and $\log$ responses, and extent of the reef. Belle River Mills Field is unique in that it has non-reef penetrations with log curves in close proximity; most Niagaran reef fields do not have such surrounding nonreef penetrations that can be used to constrain gridding.

\subsubsection{Core Permeability and Core Porosity Statistics, Belle River Mills Field, St. Clair County, Michigan}

Thirty-four of the 54 wells in the field were continuously cored through the Niagaran Reef, the A1 carbonate/anhydrite and/or the reef rubble. The cores were analyzed to produce more than 6000 measurements of air permeability and helium porosity for the reef; however, the core permeability measurements are not Klinkenberg corrected and the core porosity measurements are not overburden corrected.

Core permeability versus core porosity crossplots by rock type and core permeability and core porosity histograms by rock type are shown in Figures 9 and 10. Core permeability measurements range from zero to seven darcies with both the low and high values affected by equipment measurement limits; $50 \%$ of the permeability measurements are less than 2 millidarcies (md) while $40 \%$ range from 2 to $100 \mathrm{md}$. Core porosity ranges from zero to $33 \% ; 15 \%$ of the porosity measurements are less than 2\% while $83 \%$ range from 2 to $20 \%$. There is no apparent relationship between the core permeability and core porosity by rock type based upon the trends seen in the crossplots shown in Figure 9. Core porosity averages fall into a narrow range from 9.4\% to $10.7 \%$ (Figure 10). Core permeability averages (Figure 10) vary by rock type with the boundstone rock type having the highest over all average permeability, $260 \mathrm{md}$. The wackestone has an average permeability of $78 \mathrm{md}$ and the stromatolite rock type has an average permeability of $11 \mathrm{md}$. The reef rubble conglomerate has a permeability average of $48 \mathrm{md}$.

Permeability visualization is difficult because of the great range in values typically measured in reservoirs and especially in carbonate reservoirs. In order to visualize the permeability trends in the Belle River Mills field it was necessary to first study the distribution of the permeability values. Cumulative percent plots were constructed for all the permeability values and for each rock type (Figures 11a and b). Approximately $50 \%$ of the permeability measurements were $10 \mathrm{md}$ or greater. Based upon the cumulative percent plots it was decided (qualitatively) that if the reservoir rock had a measured permeability of greater than $30 \mathrm{md}$, it would be considered excellent reservoir rock and the values higher than $30 \mathrm{md}$ would be reset to $30 \mathrm{md}$. This had the effect of reducing the range of permeability measurements and facilitated imaging of the data using well log tomography and 3D visualization. This resulted in approximately 1500 permeability measurements being reset from a value greater than $30 \mathrm{md}$ to $30 \mathrm{md}$. 
Cumulative percent plots of porosity were also constructed for all porosity values and for each rock type (Figures 12a and b). These plots clearly show the narrow range of porosity in the reservoir and that the four rock types have very similar ranges of porosity. Modifications were not applied to the porosity data for well log tomography or 3D visualization.

\subsubsection{Well Log Tomography}

Log curve amplitude slicing was used to create a series of amplitude slices from the core permeability and porosity curves in the Belle River Mills Field. Animations of the permeability and porosity slices show the detailed distribution of these important reservoir properties throughout most of the pinnacle reef. Integrating the core porosity and permeability animations and animations of the gamma ray curve with Gill's (1977) rock types and formation tops produces a detailed reservoir model (one foot vertical resolution for tomography) that can be used to estimate the likely permeability and porosity distributions for the entire field as well as for less densely drilled and cored Niagaran pinnacle reefs.

\section{Bottom-up Slicing}

Using the bottom-up log curve amplitude slicing technique, 500-slice animations of core permeability, core porosity, and gamma ray amplitude were created through the Belle River Mills Field. Core permeability slice 175 is shown in Figure 13 and this figure is used here to orient the reader to upcoming figures. Slice 175 is located 175 feet above the base of the reef (note horizontal bar on right of figure next to core permeability curve shows the location of the slice). The slice shows two areas of high permeability separated by an area of lower permeability in mid-reef. Use of pseudo points or a zero permeability reservoir outline (the outline was taken from Gill, 1977, $\mathrm{p}$. 78, Figure 3-14) to constrain the minimum curvature gridding algorithm enhances the visualization of the trends in the core permeability and produces a symmetric appearance around the edges of the field; by comparison if the gridding is not constrained by a zero permeability outline the trends in the permeability data are still apparent but the gridding algorithm produces significant contour spool ups around the edges of the map due to the lack edge data points. We consider it reasonable to use a zero permeability outline for Niagaran reef reservoirs to constrain the gridding and imaging because these reefs are usually encased by low or zero permeability evaporites and carbonates. However, some operators in the Michigan Basin have reported high permeabilities to the very edge or skin of these reefs and some reefs have been reported to have tight cores plugged by salt and surrounded by permeable rims that comprise the reservoir.

Eight representative core permeability slices are shown in Figure 14. These slices are map view images of the distribution of permeability in the wackestone at 75, 100, 125, and 150 feet above the base of the reef and in the boundstone 175, 200, 225, and 250 feet above the base of the reef. The pattern in these eight slices show three to four 'centers of permeability' that are likely related to the original depositional fabric of the carbonate rocks. These 'centers of permeability' most probably represent individual grainstone mounds and carbonate boundstone that coalesced to form what is called the Belle River Mills Field. These eight slices as well as the full tomographic animation further indicate that the permeability is very heterogeneous varying both vertically and horizontally in the reef reservoir based upon these original depositional elements. Later dolomitization of the Niagaran reef did not eliminate the original depositional and rock property fabrics. 
The distribution of core porosity in the Belle River Mills Field is shown in Figure 15. These eight slices represent map view images of the distribution of porosity in the wackestone at 75, 100, 125 , and 150 feet above the base of the reef and in the boundstone 175, 200, 225, and 250 feet above the base of the reef. These porosity slices are at the same levels in the reef as the permeability slices shown in Figure 14 and therefore can be used to compare the distribution of porosity relative to the distribution of permeability in the reef. The patterns in the slices show three to four 'centers of porosity' in the eight images. At the scale of the whole Belle River Mills Field, the 'centers of porosity' correspond with the 'centers of permeability' and serve to reinforce the interpretation that the field is composed of individual carbonate mounds and reefs that coalesced. At a smaller scale, it is apparent there are areas with high porosity and low permeability (for example compare slice 100 in Figures 14 and 15) and other areas with both high porosity and high permeability (for example compare slice 250 in Figures 14 and 15).

The slices in Figure 16 show the contoured amplitude of the normalized gamma ray curve in the wackestone and boundstone at the same levels above the reef base as shown in the core permeability (Figure 14) and core porosity (Figure 15) figures. The eight gamma ray amplitude slices contain significantly more data control points because the gamma ray curve is available in all wells in and adjacent to the Belle River Mills Field. A zero gamma ray boundary was used to constrain the gridding algorithm and in order to compare this figure with the permeability and porosity eight-slice figures. Clearly the gamma ray amplitude in wells outside the boundary of the reef is not zero but the stratigraphy does change from the Niagaran to the younger Salina that seals and incases the reefs and these lithologies typically have low (clean) gamma ray amplitudes (using a gamma ray boundary value of 5 or 10 api units would simple decrease the apparent amplitude transition near the edge of the reef). The greater density of control points in the gamma ray slices allow for more detailed patterns to be recognized in the gridding of the gamma ray amplitudes. It is unclear at this time what the variation in the gamma ray amplitudes from well-towell especially near the edges of the reef represents. One possible explanation is that the patterns in several of the slices (slices 75 through 150, Figure 16) could represent a central lagoon (blues) ringed by shoals or islands (yellows and oranges). The higher gamma ray amplitudes could represent original depositional variations and/or early diagenetic effects related to the water table typical of this type of environmental setting. Subsequent dolomitization of the reef did not eliminate these variations. The patterns apparent in the gamma ray amplitude slice sequence in Figure 16 could also represent a small increase in water depth (slice 75 to slice 250) occurred at this time. This slight deepening in water depth could have resulted in the change from wackestone to boundstone rock type and the change from higher gamma ray amplitudes (yellows, slices 75 to 150) to lower gamma ray amplitudes (mostly blue, slices 175 to 250 ).

A comparison between two core permeability, core porosity, and gamma ray amplitude slices is shown in Figure 17 to demonstrate the similarity in the patterns observed in the contoured amplitudes of these three data types. Slice 145 from the wackestone and slice 324 from the upper boundstone or base of the stromatolite are located 145 feet and 324 feet, respectively, above the base of the reef. Slice 145 shows a close parallelism between the distribution of core permeability amplitudes and the distribution of core porosity amplitudes at this level in the reef. In contrast, Slice 324 shows much lower core permeability amplitudes (less than $4 \mathrm{md}$ ) in the northern portion of the reef where the core porosity amplitudes remain above $8 \%$. Three to five permeability and porosity centers or amplitude patterns representing centers of mound and/or reef growth may also 
be observed in these slices. Comparing the patterns from the core permeability and core porosity slices with the gamma ray amplitudes for slice 145 and 324 suggest that the best permeability and porosity is located in the central or lagoon area (blues, low gamma ray, cleaner) of the coalesced reefs based upon using the higher gamma ray amplitudes as an indicator of shoaling/emergence. The full 500-slice animation shows this pattern to be consistent from the wackestone upward through the boundstone and stromatolite rock types. Gill (1977) described the upper most rock type in the Belle River Mills Field to be stromatolite suggesting that either the boundstone reef grew to reach the water surface transitioning to shoals and/or islands (stromatolite rock type) or that the water depth decreased or a combination of reef growth and a decrease in water level took place.

\subsubsection{D Visualization}

In order to fully image the distribution of core permeability and core porosity in the Belle River Mills Field it was necessary to view the core and log curve data in 3D space. Permeability greater than $30 \mathrm{md}$ was reset to $30 \mathrm{md}$ for the 3D imaging to improve gridding and visualization results by creating a narrower range for the core permeability data (refer to Figures 10 and 11). Utilizing the 3D visualization module of the Rockware 2002 software allowed the full imaging of these data for the reef. After testing various model resolutions and gridding algorithms it was determined that the voxels in the model would measure approximately 100 feet in the $\mathrm{x}$ - and $\mathrm{y}$-directions and five feet in the z-direction; this resulted in the most realistic appearing reef models. Smaller (finer) voxels resulted in models appearing pixelated/voxelated while larger (coarser) voxels did not provide sufficient resolution. The anisotropic inverse-distance 3D gridding algorithm was used to generate final models; this algorithm assigns a voxel node value based on the weighted average of neighboring octants around each data point.

The 3D imaging software allows any range or value of core permeability to be displayed or turned on or off. The inflection point in the core permeability cumulative frequency plot and the cumulative frequency curve slope (Figure 11) where used to iterate through more than 50 visualizations or combinations of ranges of the core permeability to view continuity and connectivity of this reservoir rock property. Gill (1970) presented two average core permeability cross sections and several average isopleth maps of core permeability as examples of his statistical zonation method.

A visualization that can be conveniently described as a "Glass Reef" is shown in Figures 18 and 19. It is constructed using the core permeability voxels greater than $25 \mathrm{md}$, stratigraphy cylinders (three rock types in blues-wackestone, boundstone, and stromatolite and one rock type in greenreef rubble plus the brown non-reef Niagaran), cored intervals in wells with cores (red cylinders paralleling rock type cylinders) and the top reef structure surface (transparent gray surface of reef). What is apparent in this display is that very little of the permeability greater than $25 \mathrm{md}$ is contained within the stromatolite rock type and most of the connected permeability is located in the upper wackestone and lower boundstone. An increase in water depth was postulated to have occurred at this time in the development of the reef based upon well log tomography patterns and the change from wackestone to boundstone at this level in the reef.

Core permeability and perforated interval cylinders for each well are shown in Figure 20. The purple cylinders along each well path represent the original perforations from the State well 
records for the wells in the Belle River Mills Field. In this model, permeability voxels 20 md and greater are shown by the yellow and green colors; most of the permeability voxels higher than 25 md are obscured or behind the yellow and green voxels (refer to Figure 19). Apparent in this figure is the large interval perforated or open in each of the well bores in the reef relative to the location of reservoir rock with permeability $20 \mathrm{md}$ and greater. The large perforated interval in these wells relative to the best permeability and connectivity of this permeability could impact the productivity and/or injectivity of this reef whether for primary, secondary, or enhanced recovery or gas storage efforts.

In order to visualize the location and distribution of the best permeability ( $25 \mathrm{md}$ and greater) and the best porosity (greater than 13\%) two 3D models were created where these two different types of data could be displayed simultaneously. The porosity voxels greater than $13 \%$ were highlighted in a red color only along their edges and the permeability voxels $25 \mathrm{md}$ and greater where displayed using a solid green color for the voxel (Figures 21 and 22). Figure 21 highlights the relationship between the permeability, porosity and perforations. Figure 22 highlights the relationship between the permeability, porosity and the four rock types of the reef. Obvious in both figures is the high porosity and low permeability zone in the northern portion of the field that is predominantly composed of boundstone rock type. This area of the reef reservoir may be composed of mostly moldic-type porosity with limited connectivity. In some areas of the reef high permeability reservoir is coincident with high porosity reservoir while in other areas of the reef high permeability reservoir is coincident with reservoir porosity below $8 \%$. The best permeability and porosity are not always coincident, a conclusion that could be interpreted from the crossplots shown in Figure 9 but not apparent until the data are visualized in 3D space. Knowing the likely location of the best permeability and/or porosity in the reef reservoir and especially relative to each other could play an important role in the performance of this or other reef reservoirs undergoing primary, secondary, or enhanced recovery or gas storage operations.

\subsection{Log Curve Amplitude Slicing in the Chester 18 Field, Otsego County, Michigan}

The Chester 18 Field is located in the northern reef trend (Figures 1 and 4), covers an area of about 600 acres, and was discovered in 1971 (Figure 23). The field has produced over 13.5 million barrels of oil (MMBO) and 11 billion cubic feet (BCF) of gas from 20 vertical and deviated wells from a depth of $5900 \mathrm{ft}$. Waterflooding was initiated in 1978 by converting eight of the producing wells to water injectors. Approximately 5.5 MMBO has been produced through secondary recovery. The field is currently producing $1880 \mathrm{BO}, 21882 \mathrm{CFG}$, and $9500 \mathrm{BW}$ per month (DNR, June 2003).

The gamma ray curve from 25 vertical and deviated wells in the Chester 18 Field and vicinity were scanned and digitized, but only the vertical wells were used in the gamma ray amplitude slicing (Figure 24); the computer code to allow the use of log curve amplitudes in deviated wellbores is under development. No detailed stratigraphic analysis like the work of Gill has been completed for the Chester 18 Field and core was taken in only one of the vertical wells. Only two wells penetrate the entire reef in the field and these were used along with non-reef wells to estimate the reef base in reef wells with shallower total depths. It was necessary to estimate tops for the reef base in order to place the gamma ray curves for these wells in the proper spatial (vertical) 
position relative to the reef base (null values were used to populate gamma ray amplitude values for those intervals below the actual total depth of the well for gridding).

Figure 24 shows gamma ray slice 214 ( 214 feet above the base or estimated base of the reef). The gamma ray curve on the left shows the position of the slice relative to the base and top of the reef. In this example, the reef outline was not used to constrain the gridding algorithm, therefore, anomalies (contouring spool ups) are evident around the periphery of the map in no data areas. Slice 214 shows two carbonate depositional centers that are even more evident when the full animation is viewed. Production engineering data from the operator that was released to the State as part of the application for the waterflood project also suggested the Chester 18 Field was composed of two reservoir compartments.

Additional work imaging other log curves (i.e., porosity, resistivity, sonic) using well log tomography and $3 \mathrm{D}$ visualization is planned for the Chester 18 Field.

\subsection{Surface Geochemistry in the Charlton 6 Field, Otsego County, Michigan}

Charlton 6 was sampled for surface geochemical analysis because it was scheduled as the original demonstration field for this project. The contoured results from the survey are shown in Figure 25. The high to the northeast of the St. Charlton-Zeimet \#1 well was unexpected because the field is presently at the end of its primary production life and is at a low reservoir pressure (less than $100 \mathrm{psi}$ ) which should result in a low surface geochemical signature. This may indicate that the Charlton 6 reservoir contains undrained compartments, that another reef may exist along the east edge of section 6 , or that a shallower horizon is interfering with the geochemical signature from the reef or reefs.

We intend to monitor this field via surface geochemistry and the Dover 35 Field (depending upon when injection begins versus surface access issues due to winter weather conditions) as they are filled to see if we can detect any changes in the surface geochemical signature as the reefs are repressurized using $\mathrm{CO} 2$. 


\subsection{CONCLUSION}

The site of the demonstration project was shifted from the Charlton 6 to the Dover 35 Field due to $\mathrm{CO} 2$ and pipeline availability. Contract negotiations for the supply of $\mathrm{CO} 2$ that will be injected into the Dover 35 reef were completed. The State of Michigan approved the application by our industry partner to begin the $\mathrm{CO} 2$ injection and we estimate injection will begin in February, 2004.

Well log tomography and 3D imaging of the core permeability, core porosity and/or gamma ray curves for the Belle River Mills and Chester 18 analog reservoirs is underway or has been completed. Results indicate significant heterogeneity exists in Niagaran reefs that could impact reservoir performance. This heterogeneity should be considered in the planning of primary, secondary, tertiary or gas storage projects in these types of fields. 


\subsection{REFERENCES}

Collins, D. R., 1998, Visualization of subsurface geology from wireline logs in Digital Mapping Techniques '98 -- Workshop Proceedings: U. S. Geological Survey Open-file Report 98487,< http://pubs.usgs.gov/of/of98-487/collins.html>, accessed September 30, 2002.

Friedman, G. M., and Kopaska-Merkel, D. C., 1991, Late Silurian pinnacle reefs of the Michigan Basin, in Catacosinos, P. A., and Daniels, P. A., Jr., eds., Early sedimentary evolution of the Michigan Basin: Geological Society of America Special Paper 256, p. 89-100.

Gill, D., 1970, Application of a statistical zonation method of reservoir evaluation and digitized$\log$ analysis; AAPG Bulletin, v. 54, no. 5, p. 719-729.

Gill, D., 1977, The Belle River Mills Gas Field: Productive Niagaran reefs encased by sabkha deposits, Michigan Basin: Michigan Basin Geological Society, Special Paper no. 2, 188 p.

Gill, D. 1979, Differential entrapment of oil and gas in Niagaran pinnacle-reef belt of northern Michigan: American Association of Petroleum Geologists Bulletin, v. 63, p. 608-620.

Gill, D. 1985, Depositional facies of Middle Silurian (Niagaran) pinnacle reefs, Belle river Mills gas field, Michigan Basin, southeastern Michigan, in Roehl, P. O., and Choquette, P. W., eds., Carbonate petroleum reservoirs: New York, Springer-Verlag, p. 121-139.

Huh, J. M., Briggs, L.I., and Gill, D., 1977, Depositional environments of pinnacle reefs, Niagara and Salina Groups, northern shelf, Michigan basin in Reefs and Evaporites-concepts and depositional models: AAPG Studies in Geology, no. 5, p. 1-21.

Kesling, R., editor, 1974, Silurian reef-evaporite relationships: Michigan Basin Geological Society, Field Conference, 111 p.

Leibold, A. W., 1992, Sedimentological and geochemical constraints on Niagaran/Salina deposition, Michigan Basin: Ph.D. dissertation, University of Michigan, Ann Arbor, 280 p.

Mantek, W., 1973, Niagaran pinnacle reefs in Michigan: Michigan Basin Geological Society Annual Field Conference Guidebook, p. 35-46.

Mesolella, K. J., Robinson, J. D., McCormick, L. M., and Ormiston, A. R., 1974, Cyclic deposition of carbonates and evaporites in Michigan Basin: American Association of Petroleum Geologists Bulletin, v. 58, p. 34-62.

Neinast, G. S., and C. C. Knox, 1974, Normalization of well log digitizing: The Log Analyst, v. 15 , no. 2 , p. $18-25$.

Sanford, B. V., 1969, Geological logs of the Silurian formations (formation tops) penetrated by several thousand wells drilled for oil and gas in southwestern Ontario, formation tops determined: Open File Report, Geological Survey of Canada, 4 volumes of well logs. 
Scotese, C., Bambach, R. K., Barton, C., Van der Voo, R., and Ziegler, A., 1979, Paleozoic base maps: Journal of Geology, v. 87, p. 217-277.

Sears, S. O., and Lucia, F. J., 1979, Reef-growth model for Silurian pinnacle reefs, northern Michigan reef trend: Geology, v. 7, p. 299-302.

Shier, D. E., 1997 A comparison of log response between different logging companies and different vintages of tools: The Log Analyst, v. 38, no. 3, p. 47-61.

Sloss, L. L., 1963, Sequences in the cratonic interior of North America: GSA Bull., v. 74, p. 2739.

Sloss, L. L., 1969, Evaporite Deposition from layered solutions: AAPG Bull., v. 53, no. 4, p. 776789.

Sloss, L. L., 1982a, The midcontinent province: United States, in A. R. Palmer (ed.), Perspectives in regional geological synthesis: GSA DNAG Special Pub. No. 1, p. 27-39.

Wylie, A. S., Jr., 2002, Log Curve Amplitude Slicing - Visualization of well log amplitudes for paleogeographic reconstruction of the Middle Devonian Traverse Group, Michigan Basin: Ph. D. dissertation, Michigan Technological University, Houghton, MI, 250 p.

Wylie, A. S., Jr. and Huntoon, J. E., 2003, Log Curve Amplitude Slicing - Visualization of Log Data for the Devonian Traverse Group, Michigan Basin, U. S.: AAPG Bulletin, v. 87, no. 4, p. 581-608. 


\subsection{FIGURES}




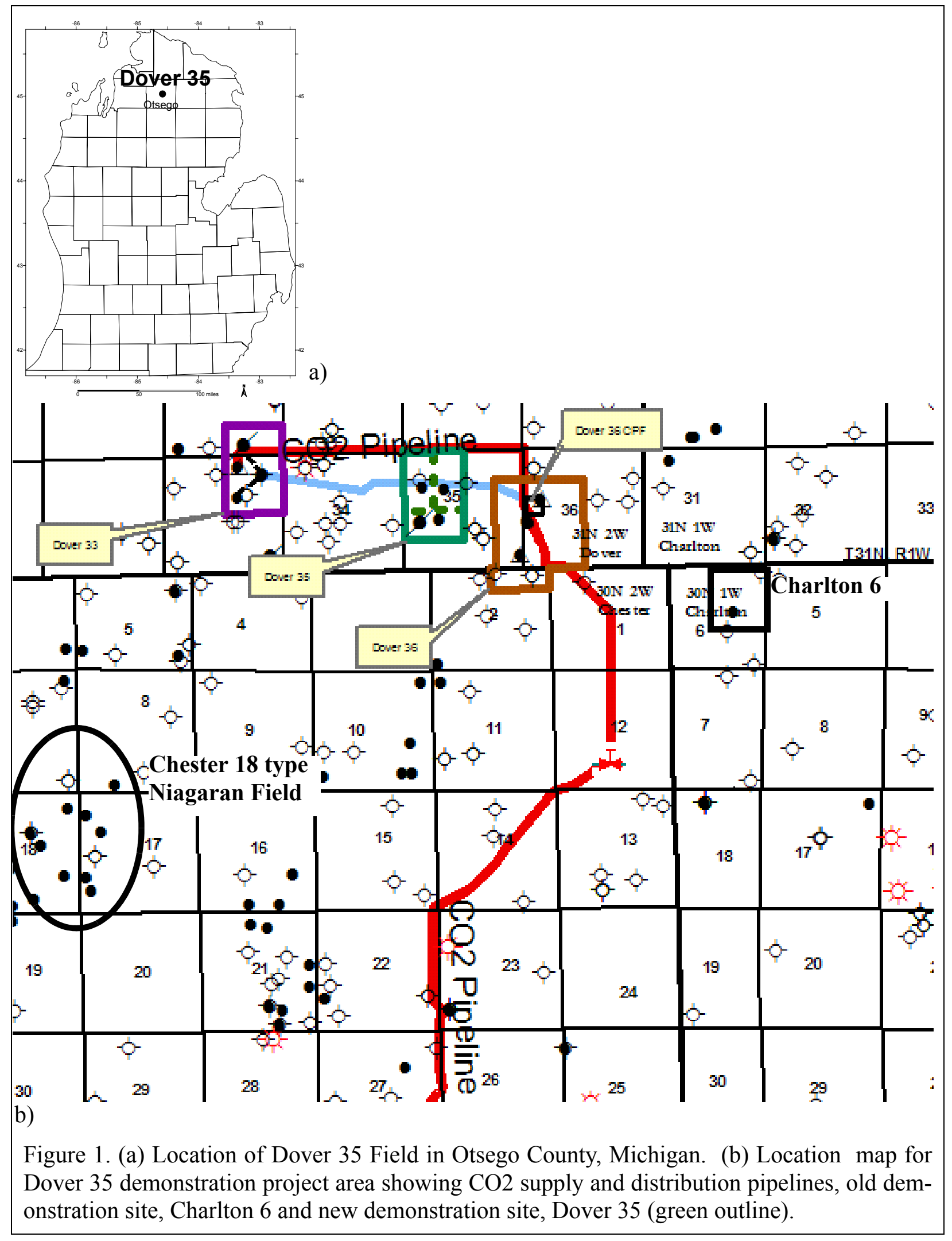




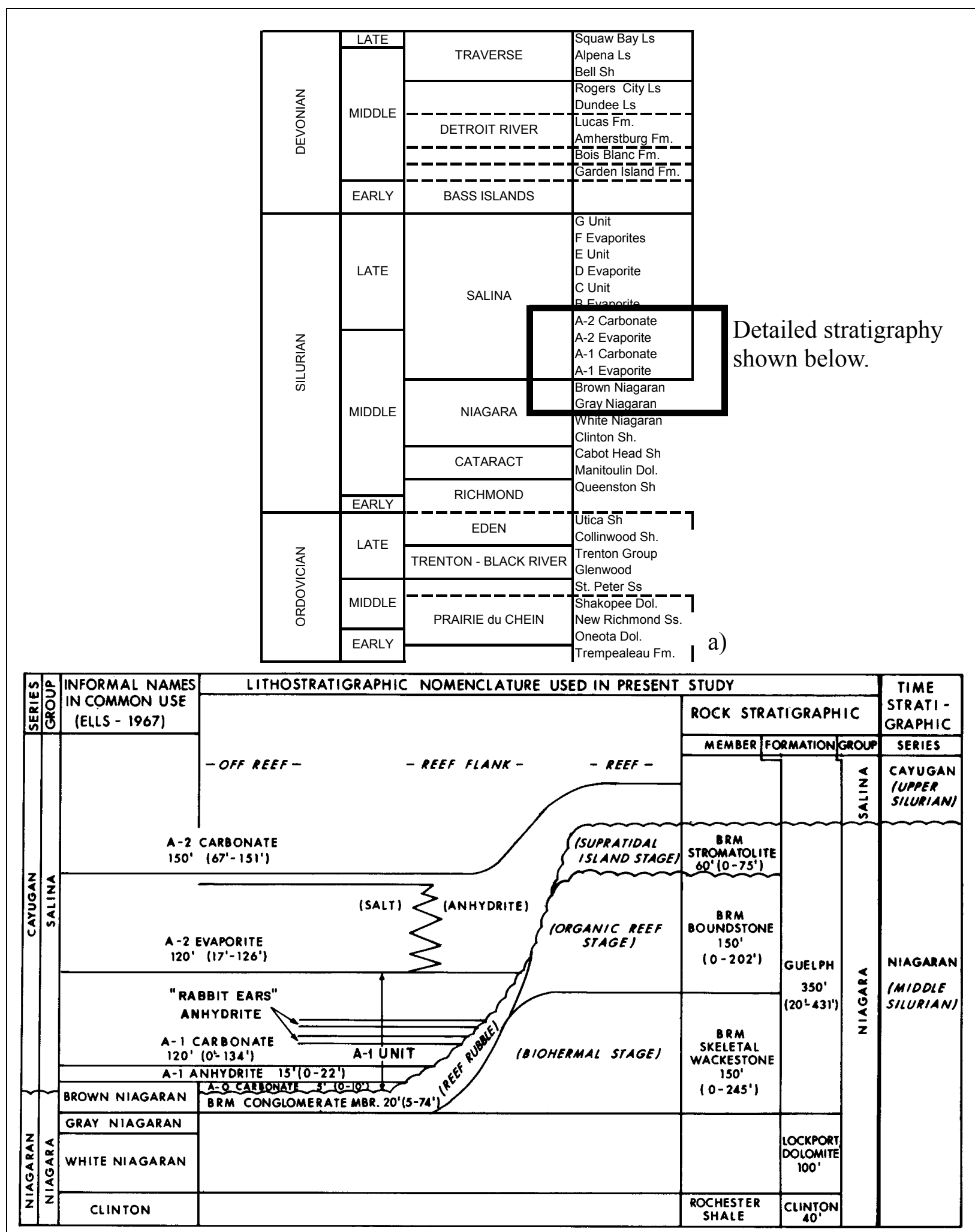

b)

Figure 2. (a) Devonian through Ordovician stratigraphic column for the Michigan Basin and (b) typical detailed stratigraphic column for a Niagaran reef and vicinity (Gill, 1977). 


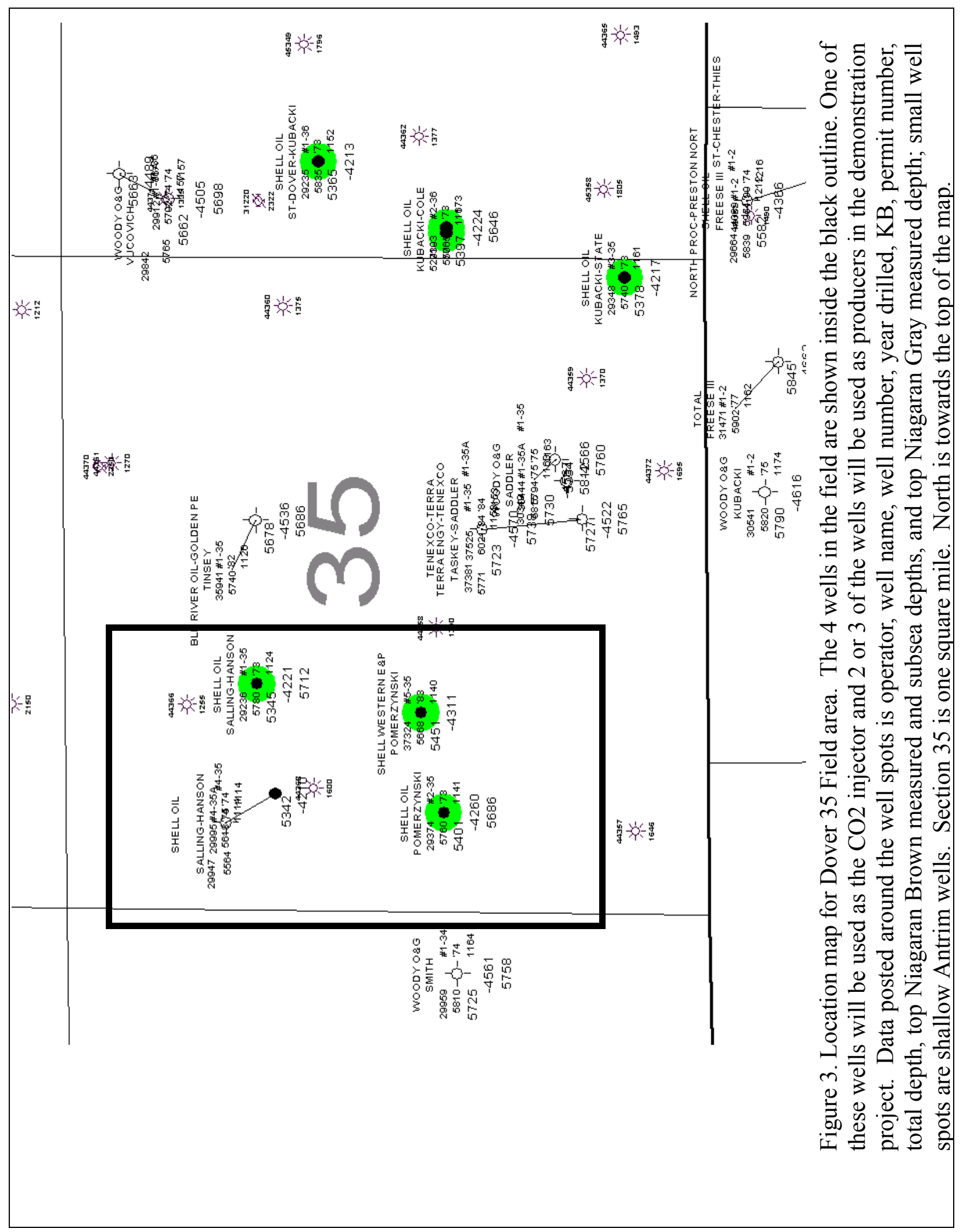




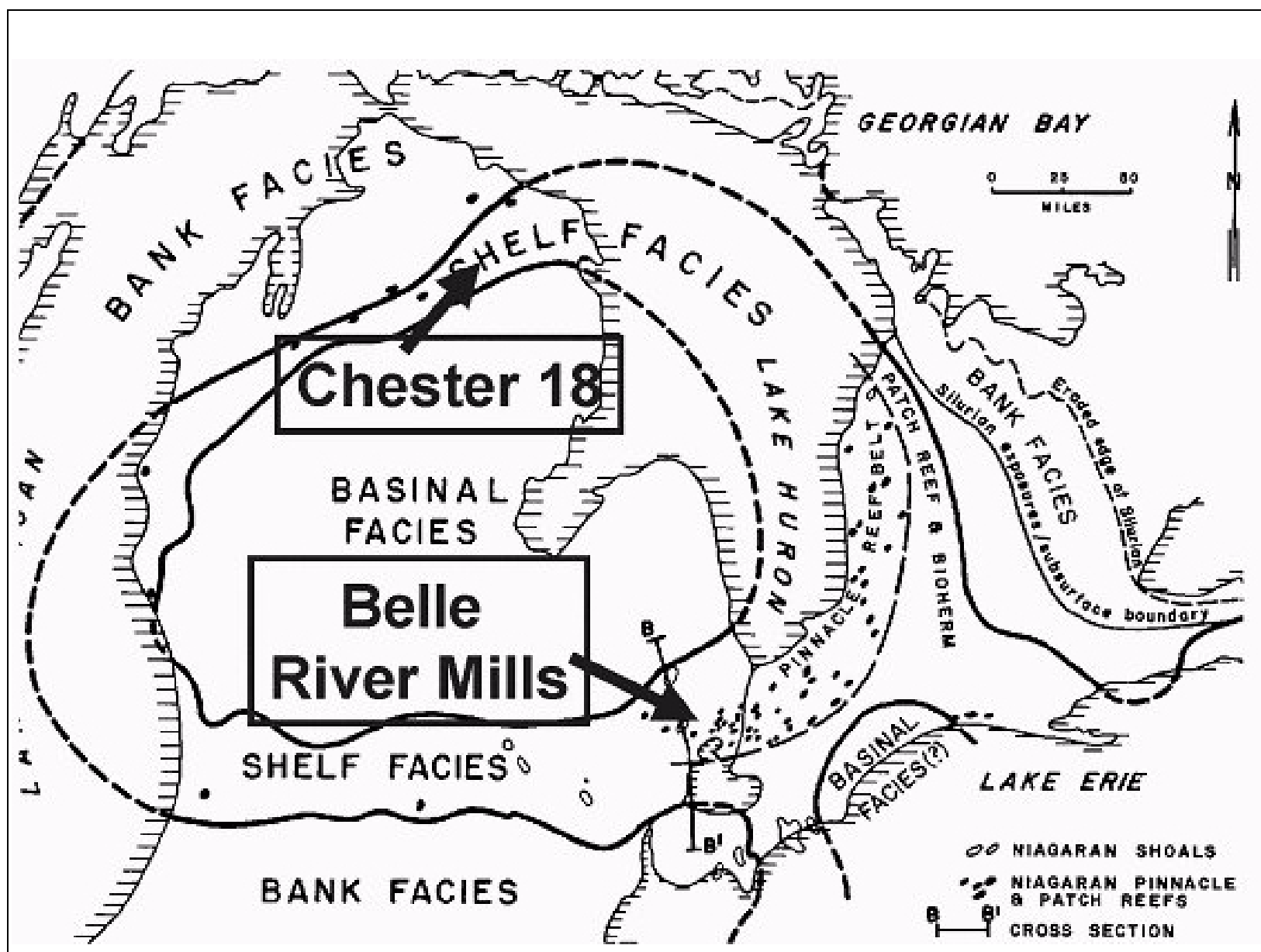

Figure 4. Map of Niagaran rocks in the Michigan basin showing three depositional trends and location of Belle River Mills and Chester 18 type Niagaran Reef Fields (Gill, 1977). 


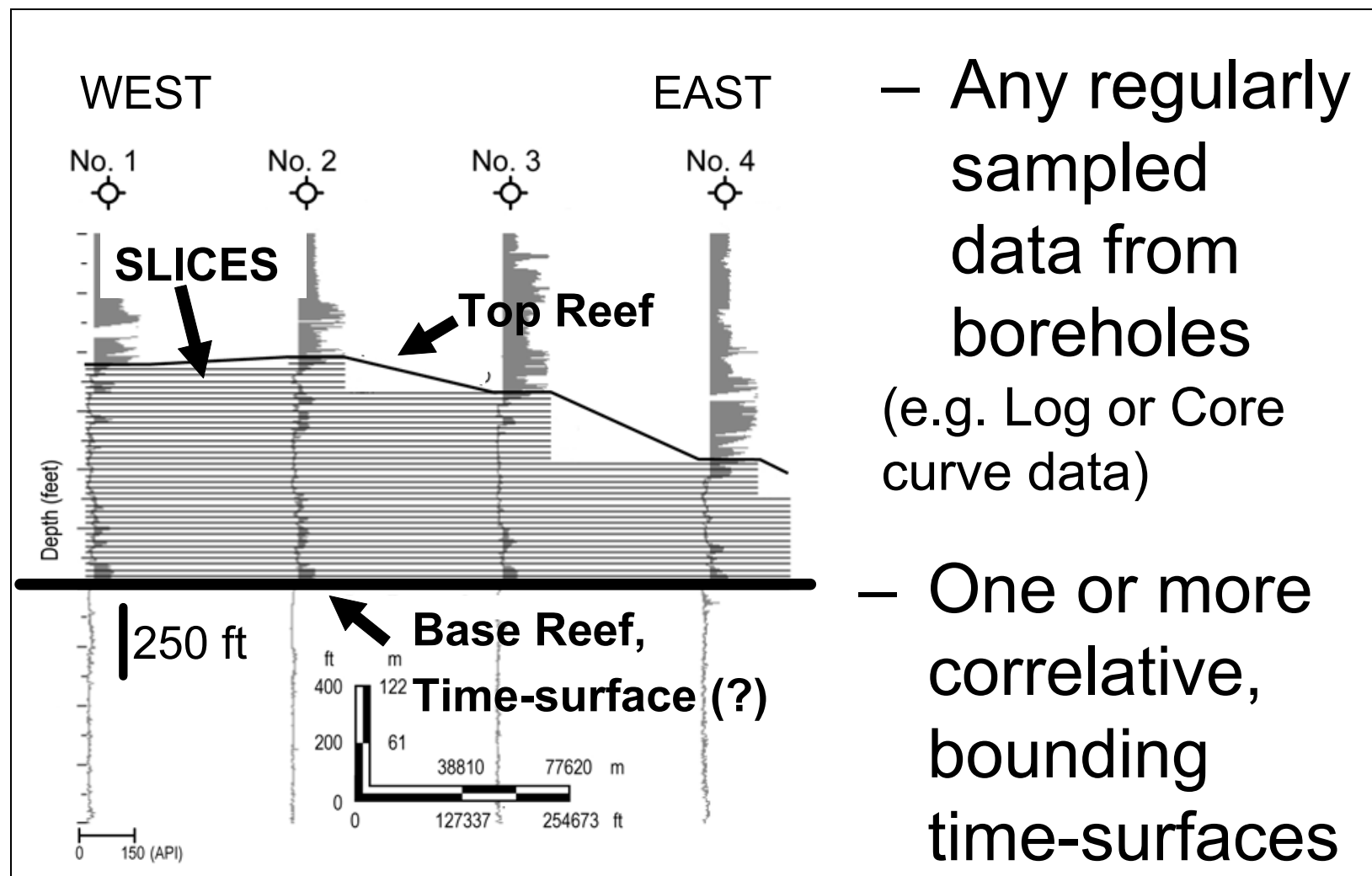

Figure 5. Summary of Log Curve Amplitude Slicing or Well Log Tomography technique showing bottom-up slicing from base of a Niagaran Reef. 


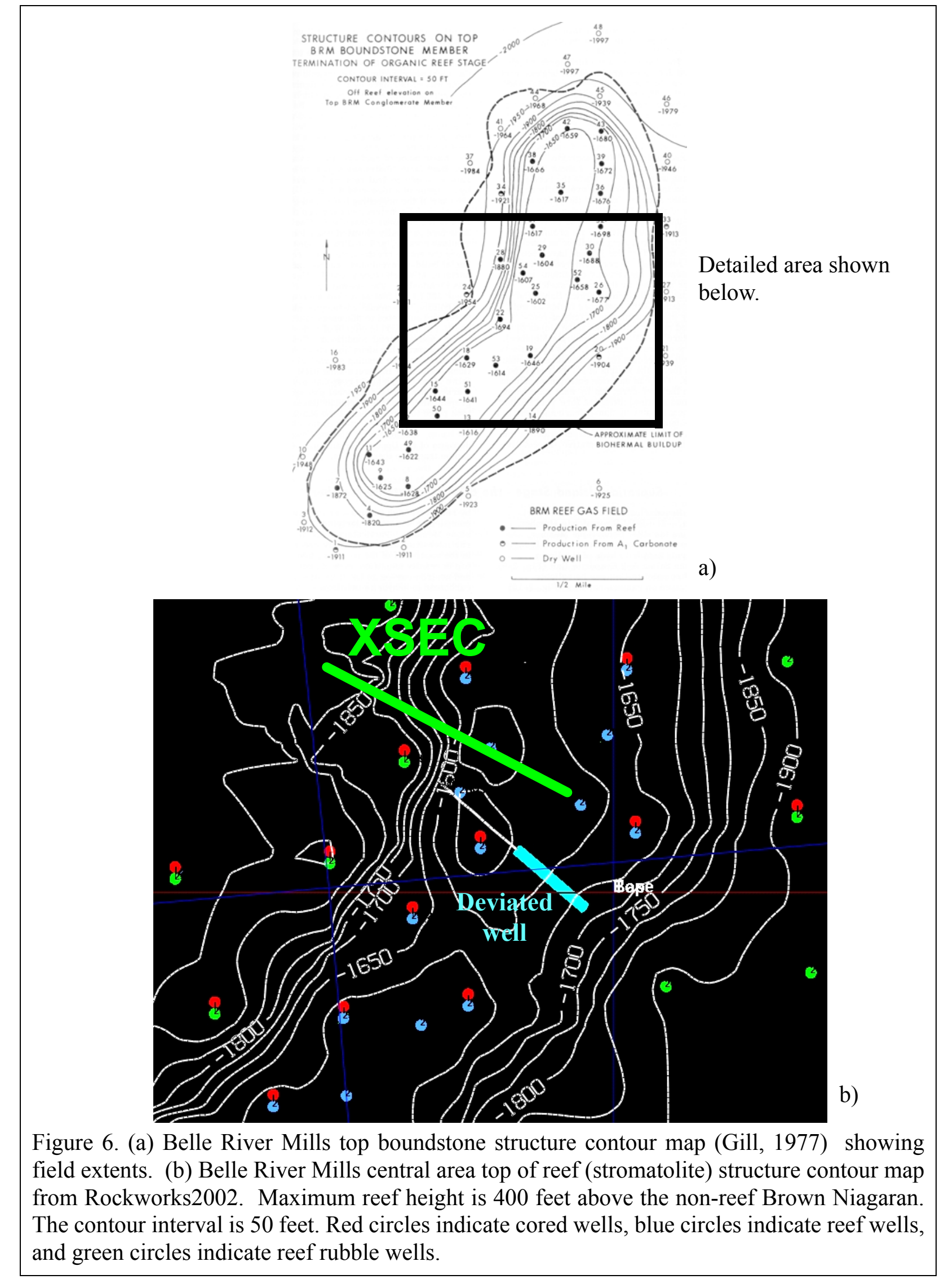




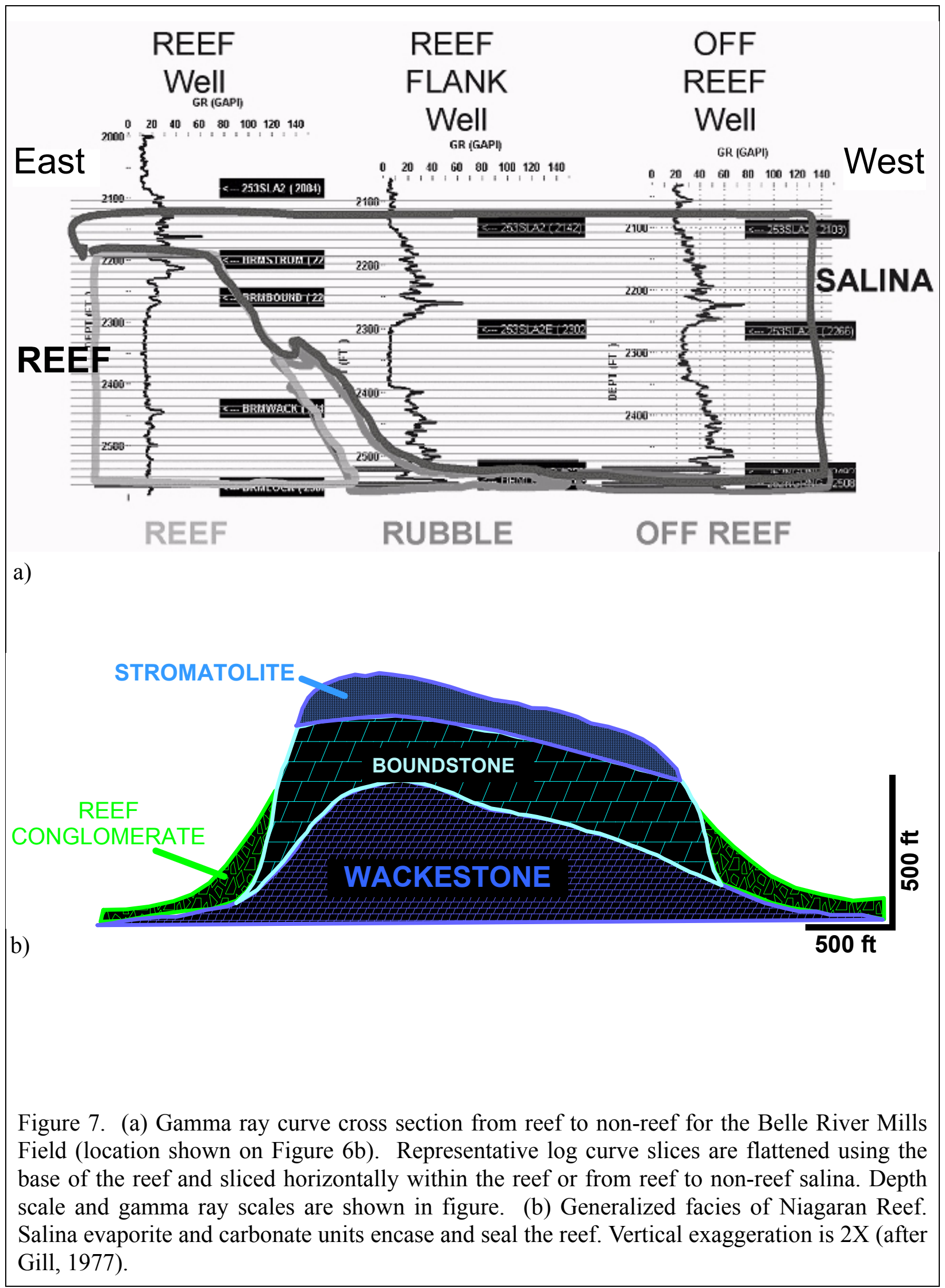




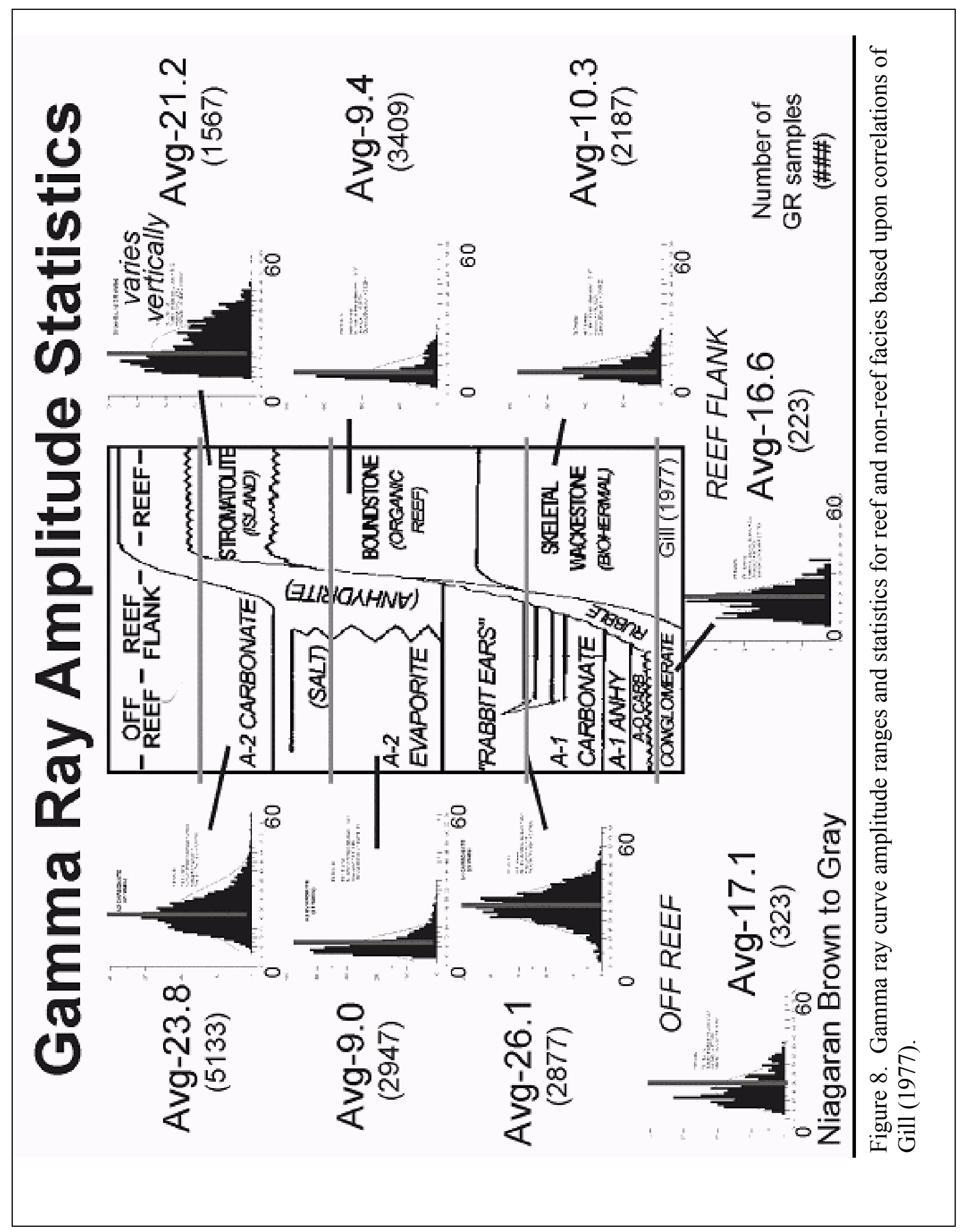




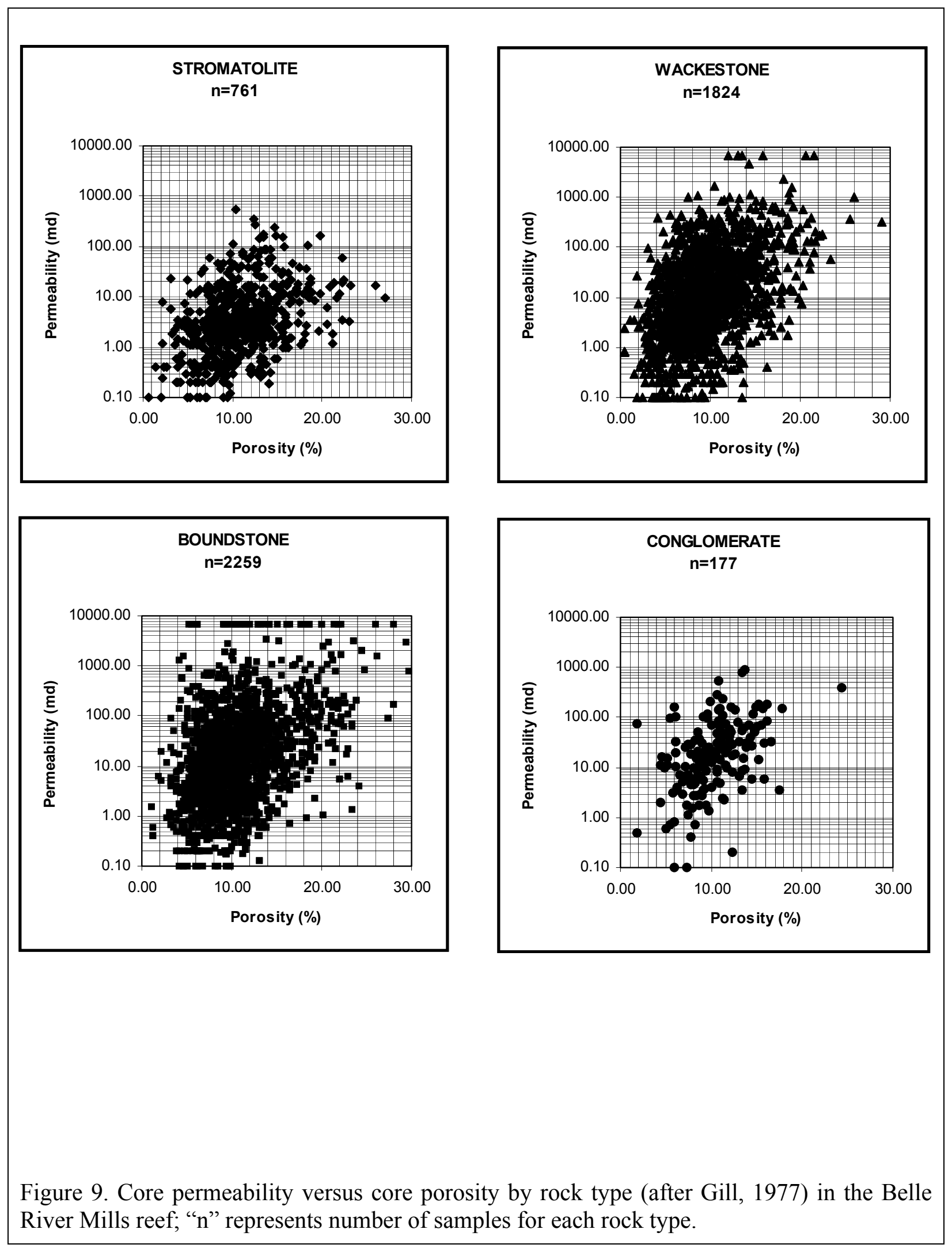




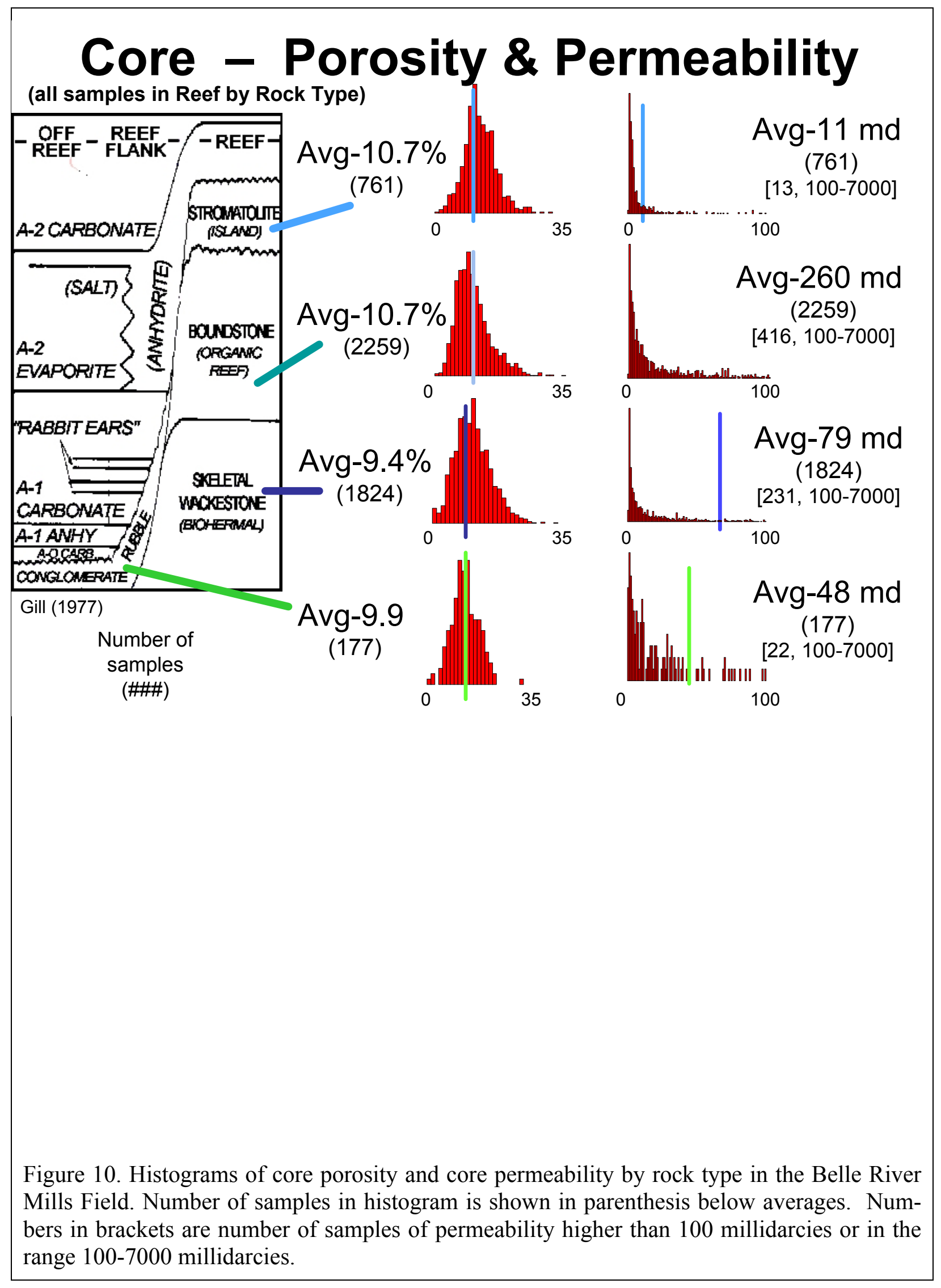




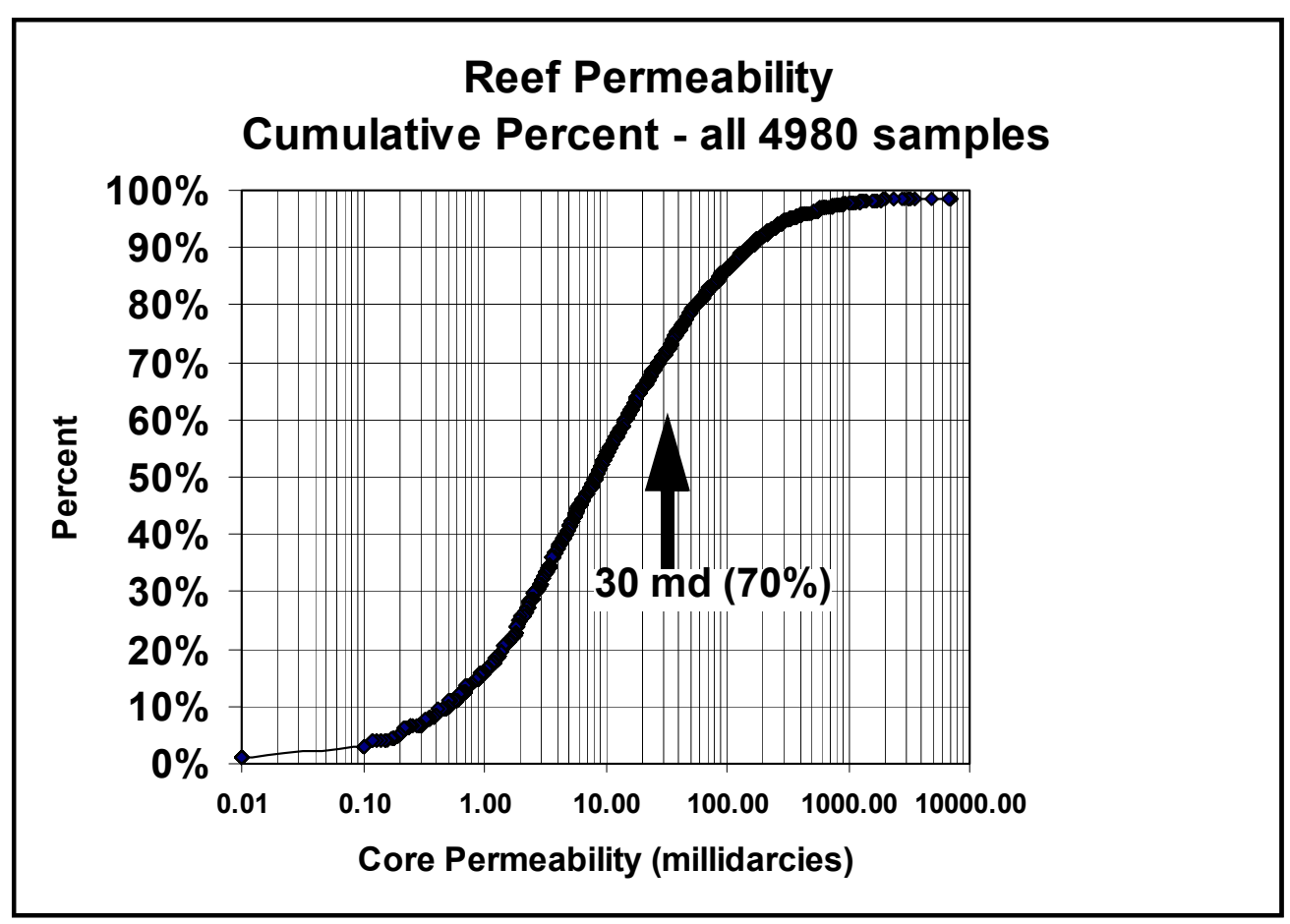

Figure 11a. Cumulative percent plot of reef core permeability for all rock types in the Belle River Mills Field, St. Clair County, Michigan.

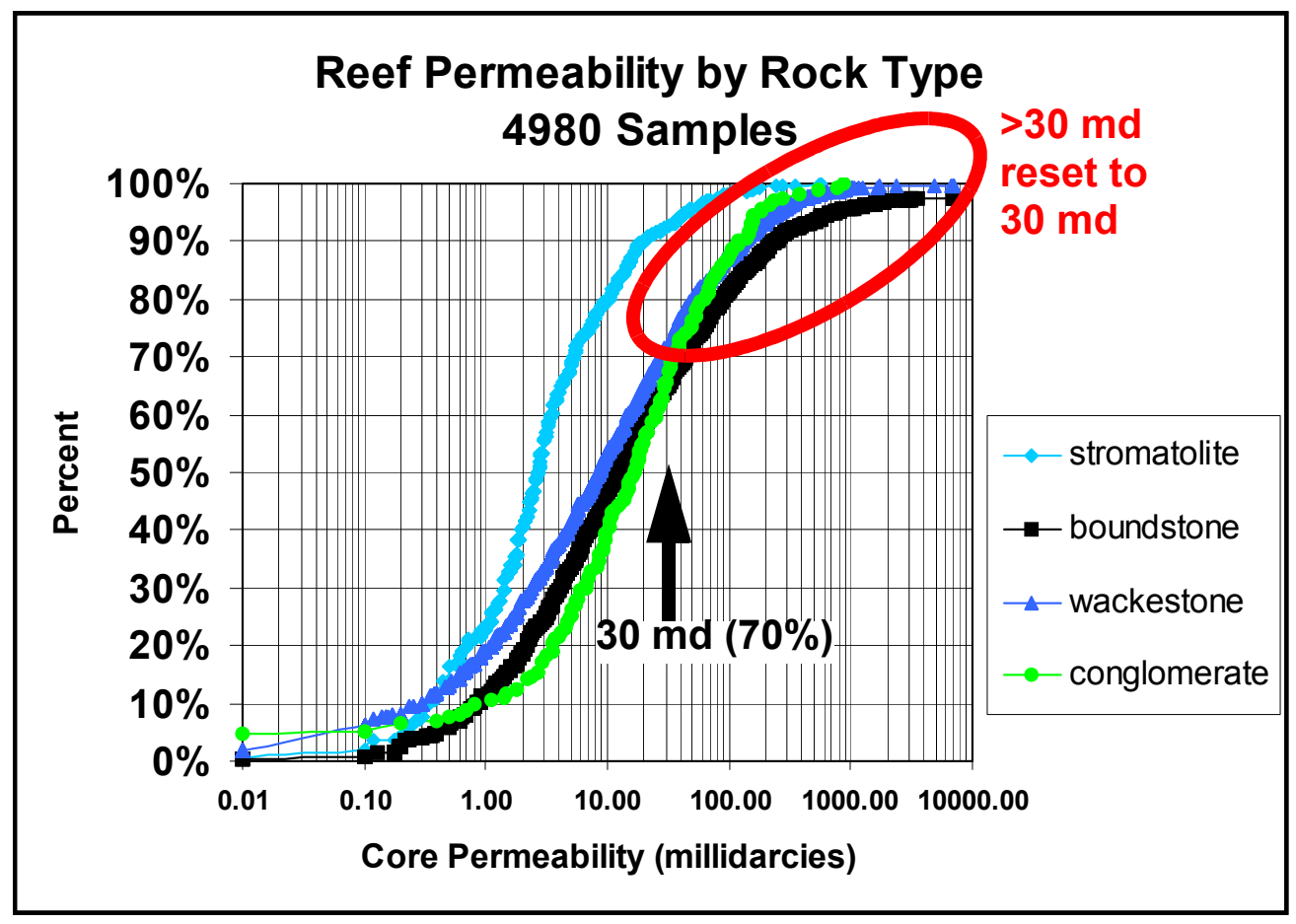

Figure $11 \mathrm{~b}$. Cumulative percent plot of reef core permeability by four rock types in the Belle River Mills Field, St. Clair County, Michigan. Permeability measurements greater than 30 md were reset to $30 \mathrm{md}$ to enable visualization of permeability trends in the $3 \mathrm{D}$ model. 


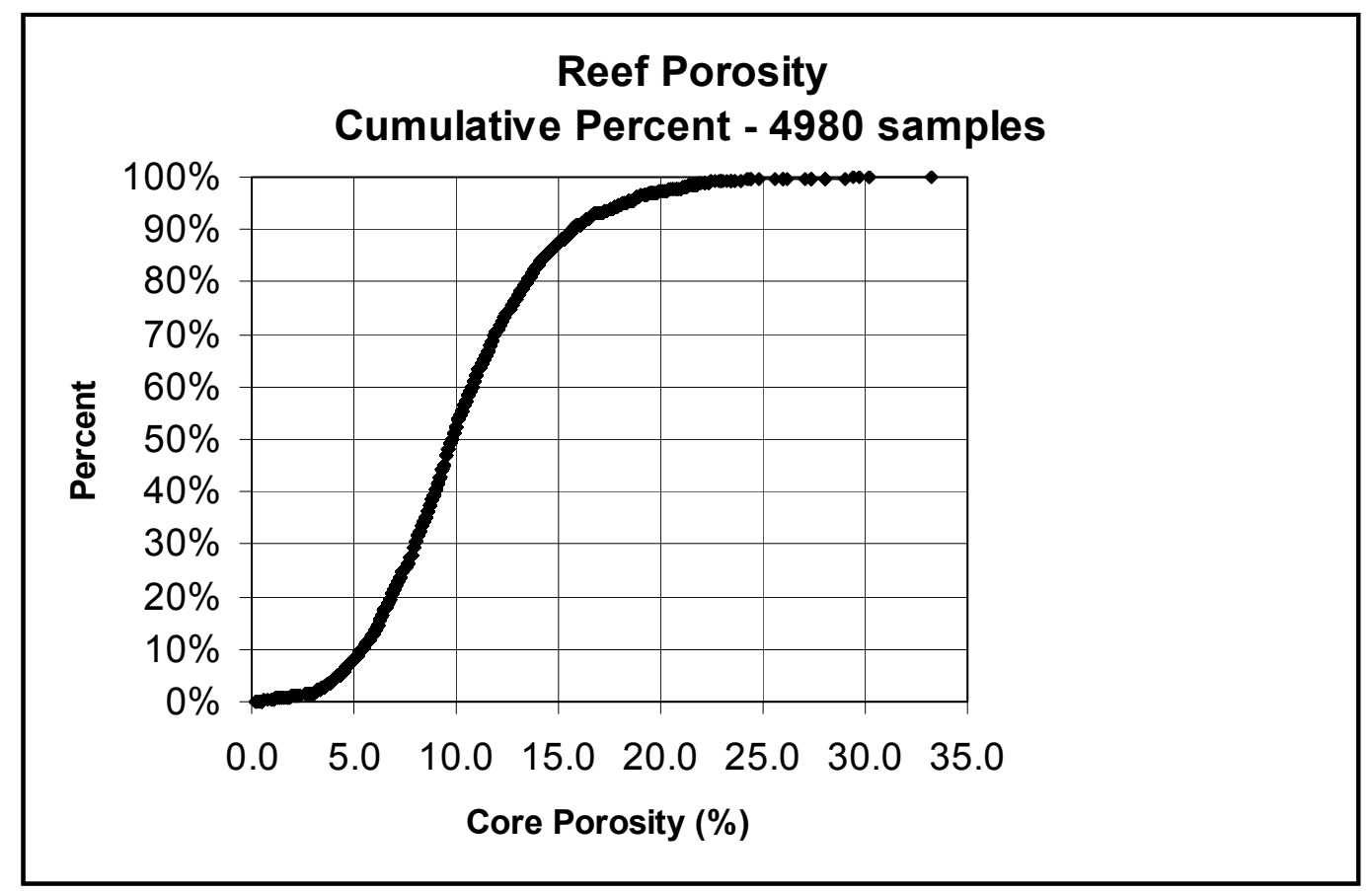

Figure 12a. Cumulative percent plot of reef core porosity for all rock types in the Belle River Mills Field, St. Clair County, Michigan.

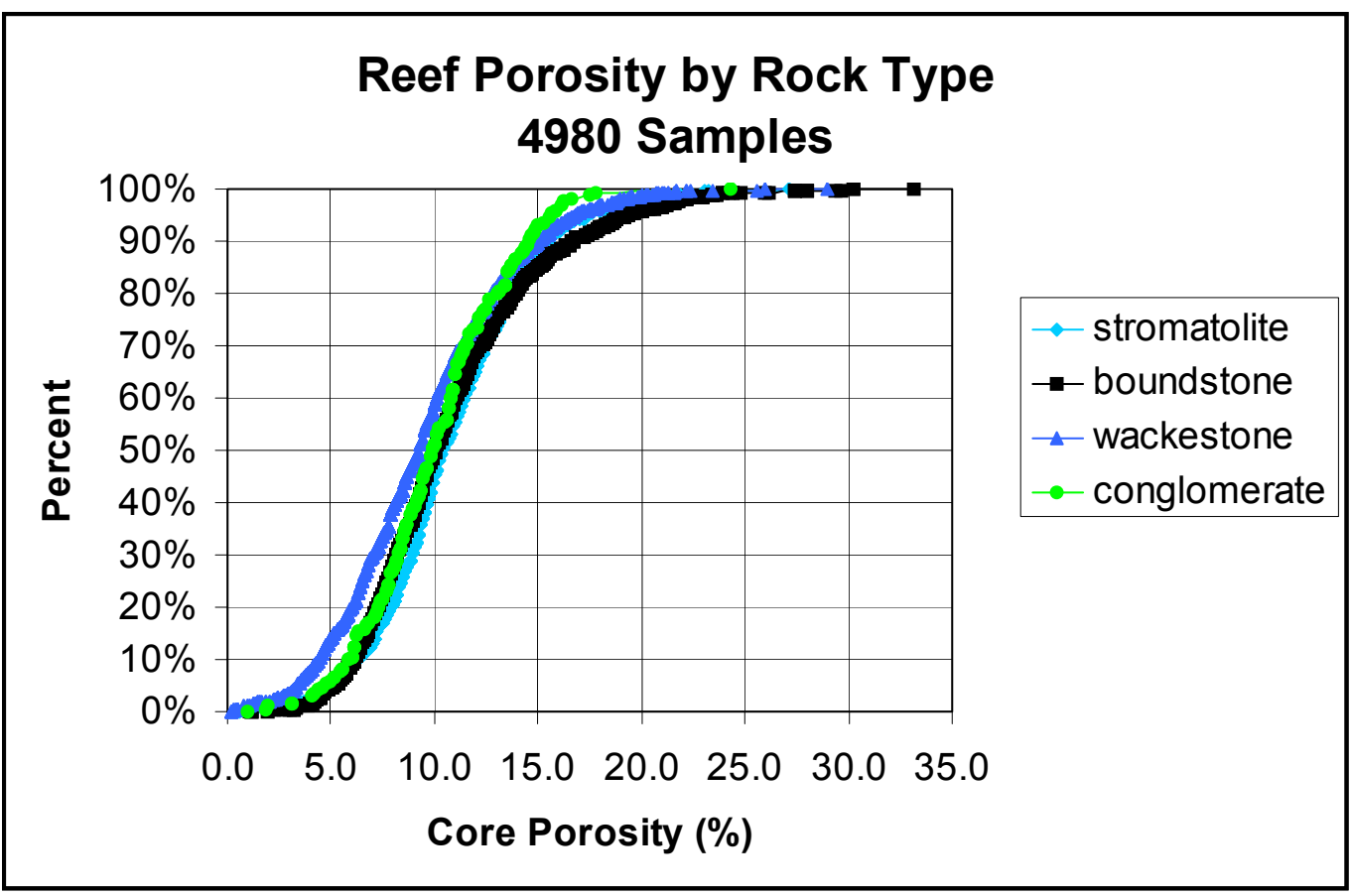

Figure 12b. Cumulative percent plot of reef core porosity by four rock types in the Belle River Mills Field, St. Clair County, Michigan. 


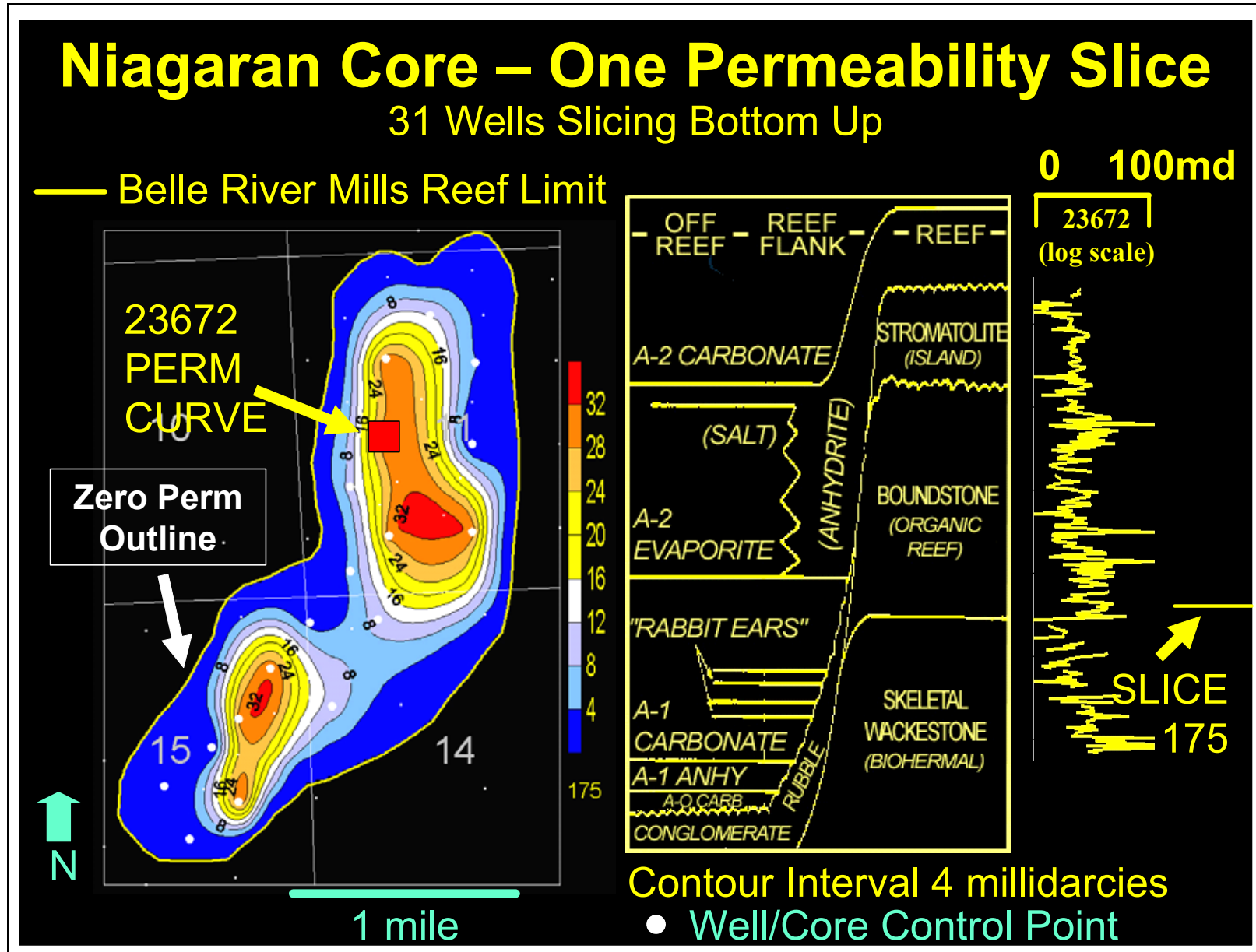

Figure 13. Log Curve Amplitude Slice number 175 from the core permeability slicing. Slice 175 is 175 feet above the base of the reef and is located in the boundstone. A zero permeability outline was used to constrain the gridding of each slice and to prevent gridding edge affects. Slice 175 is shown relative to the permeability curve and the general reef stratigraphy on the right. Large white dots are data control points on each slice and small white dots are other well locations. 


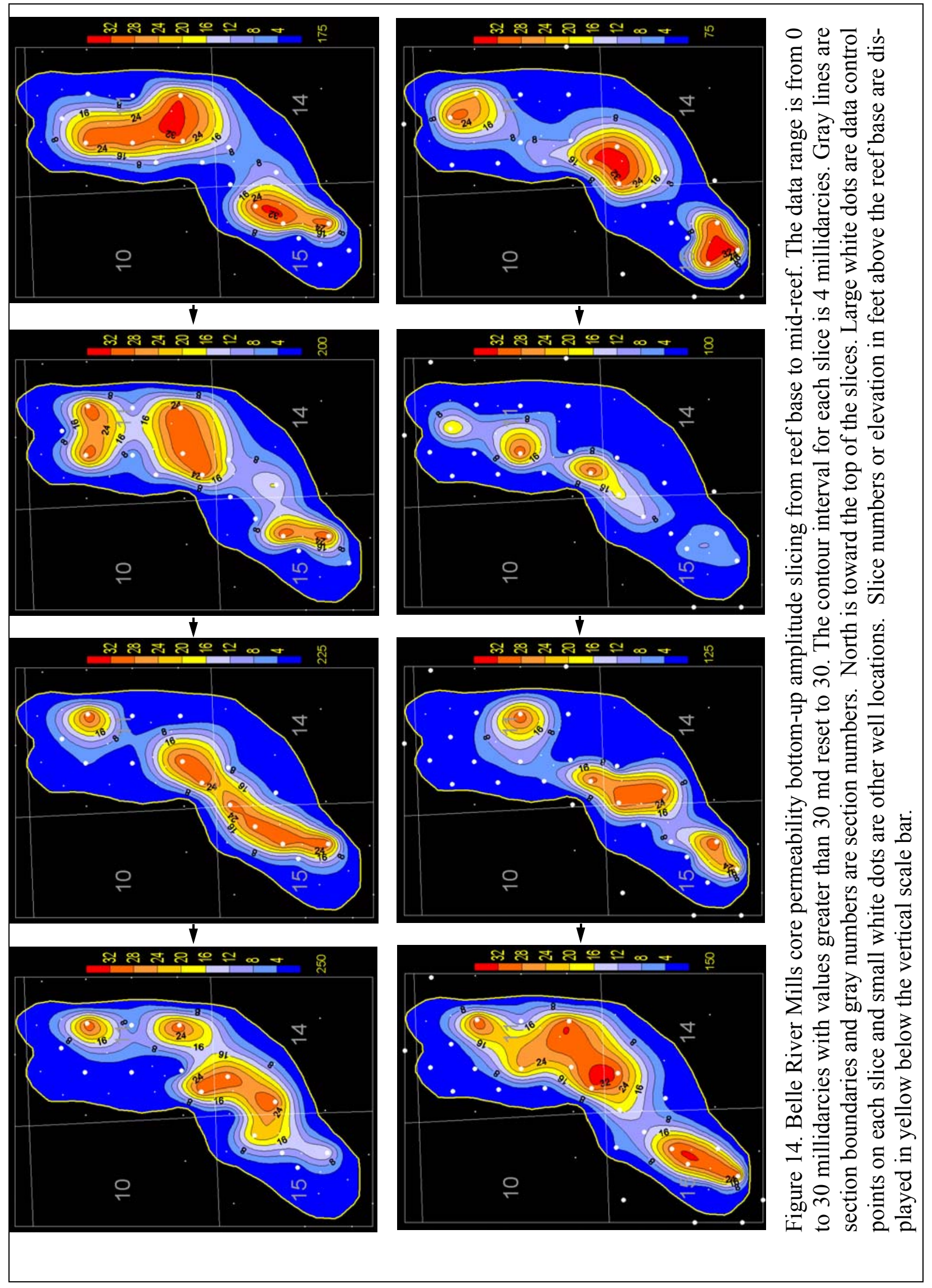




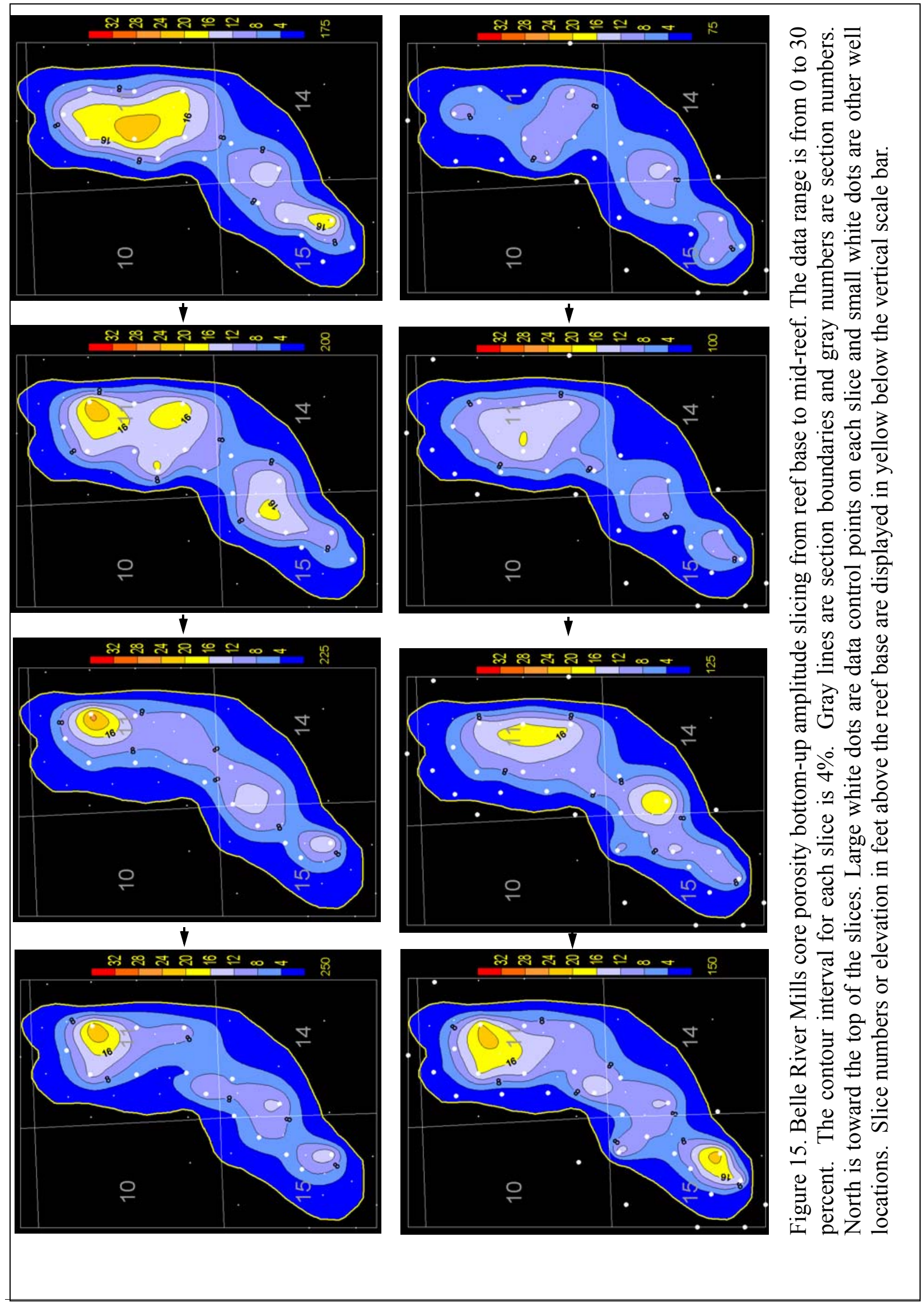




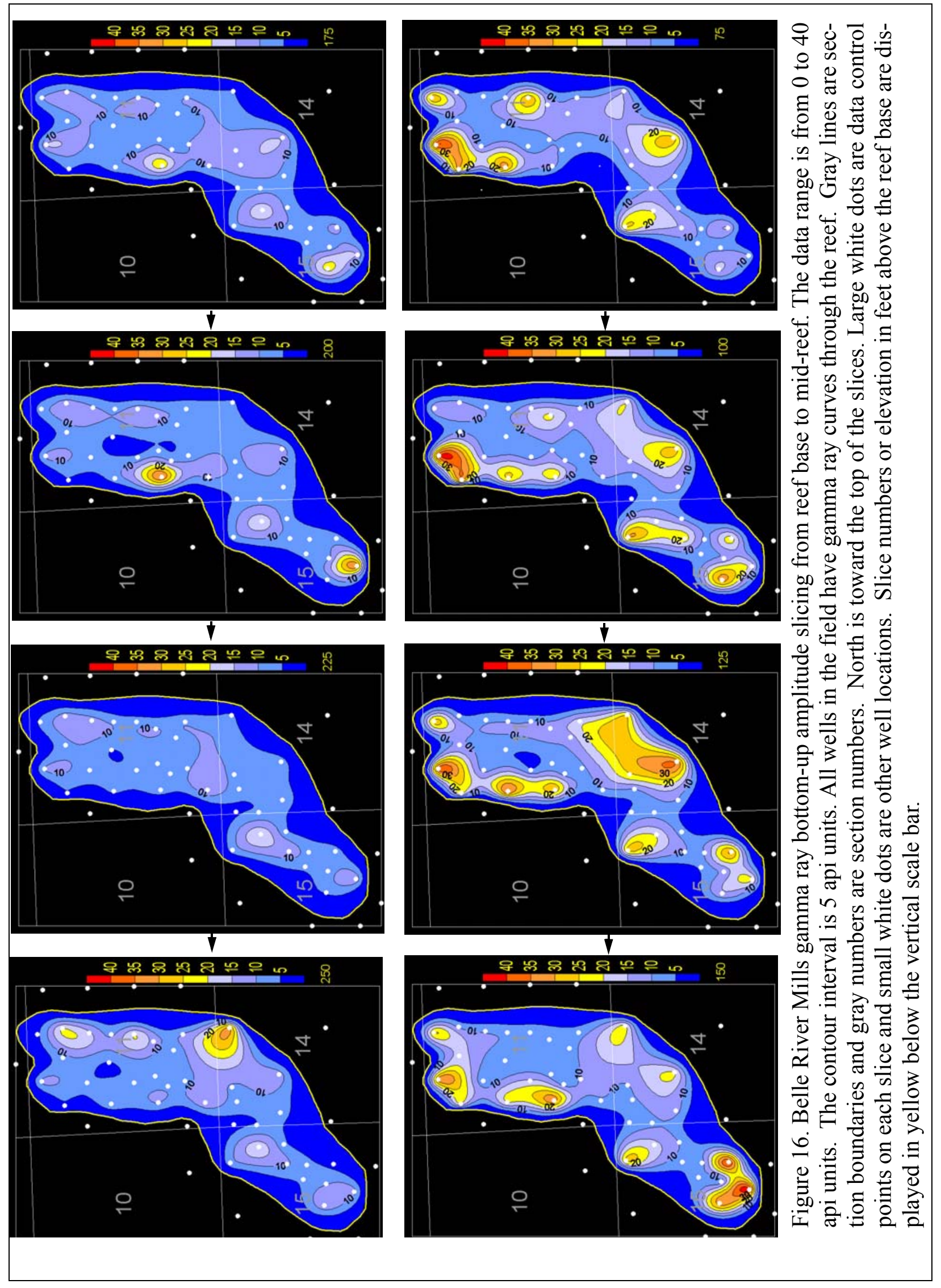




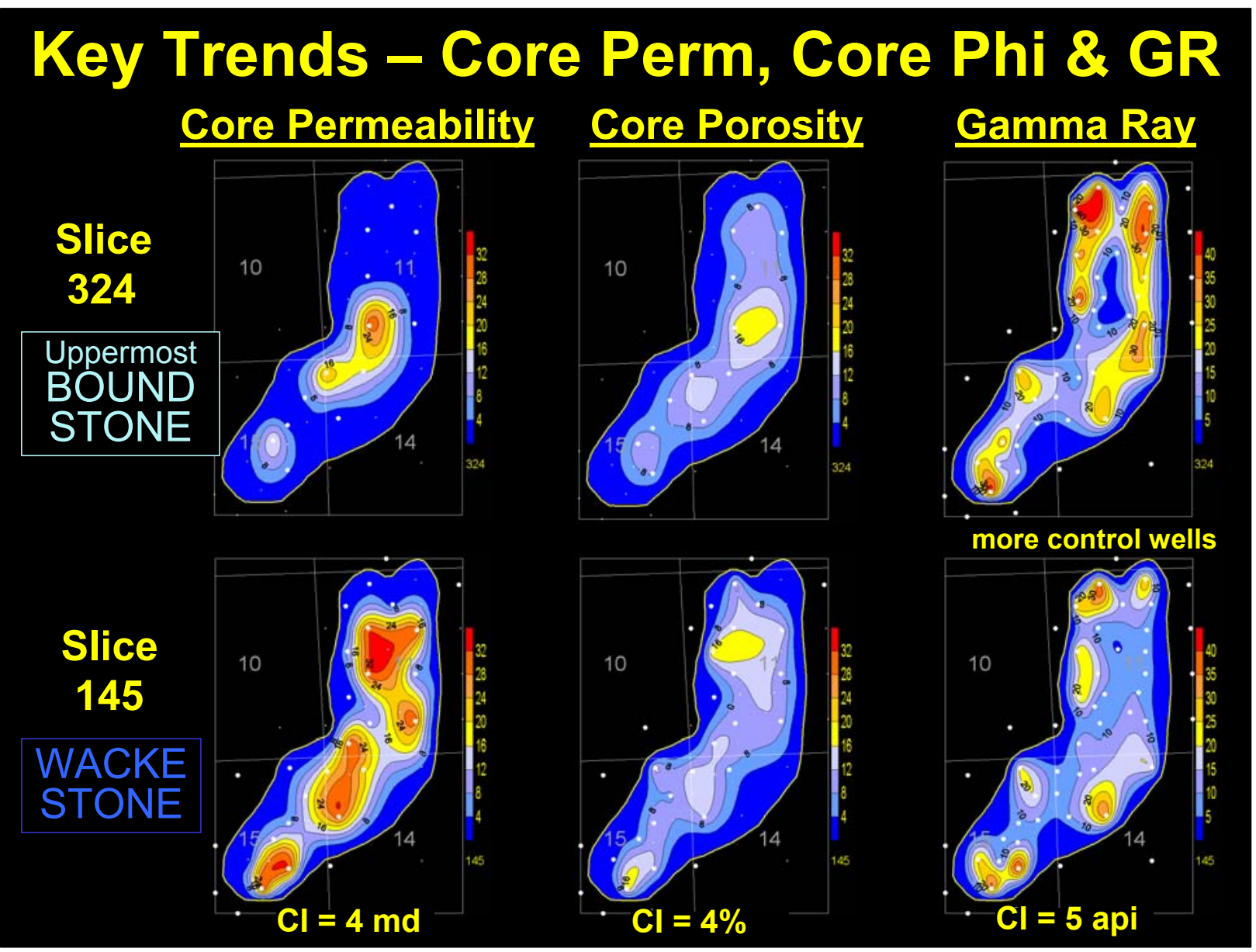

Figure 17. Comparison of two key core permeability, core porosity, and gamma ray slices from the wackestone and boundstone in the Belle River Mills Field. Note the permeability and porosity amplitude trends are approximately equivalent to the trends observed in the gamma ray amplitudes. This is an important observation and is significant in that it means we may be able to use log curve amplitude slicing of the gamma ray curves only to visualize the approximate distribution of permeability and porosity in reefs without core data (most Niagaran Reef wells have at least a gamma ray log curve) by utilizing the data from these type reefs. 


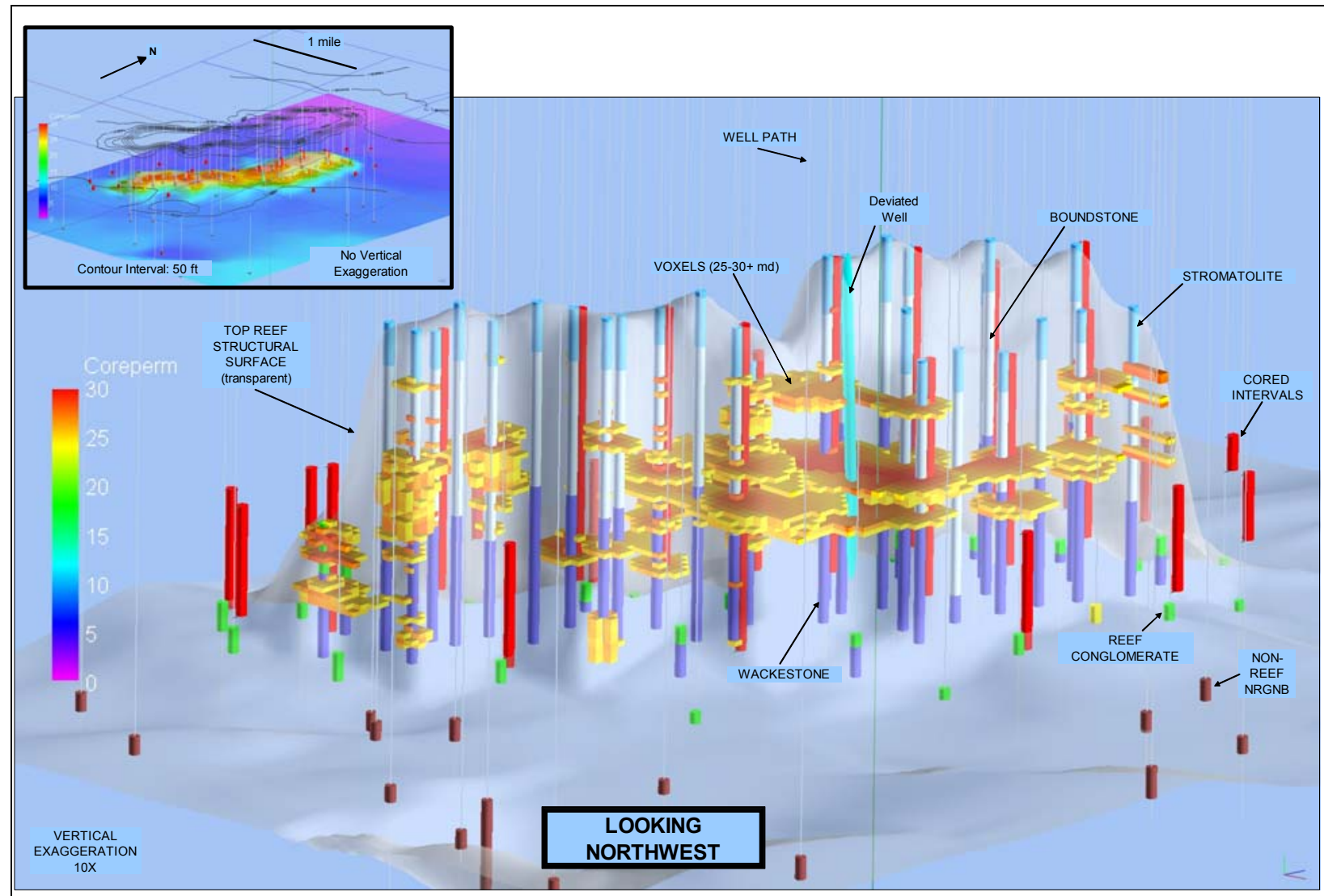

Figure 18. Belle River Mills “Glass Reef”, showing permeability voxels ( $>25 \mathrm{md}$, best quality reservoir), stratigraphy, cored intervals, and top reef structure surface. The color scale on the left is core permeability in millidarcies from 0 to 30 . Vertical exaggeration is $10 \mathrm{X}$. View is looking northwest, 30 degrees above horizontal. Inset is same display with no vertical exaggeration and top of reef structural contours and landgrid overlays. Voxel resolution is 115 feet in the $\mathrm{x}$ - and $\mathrm{y}$-directions and six feet in the z-direction. 


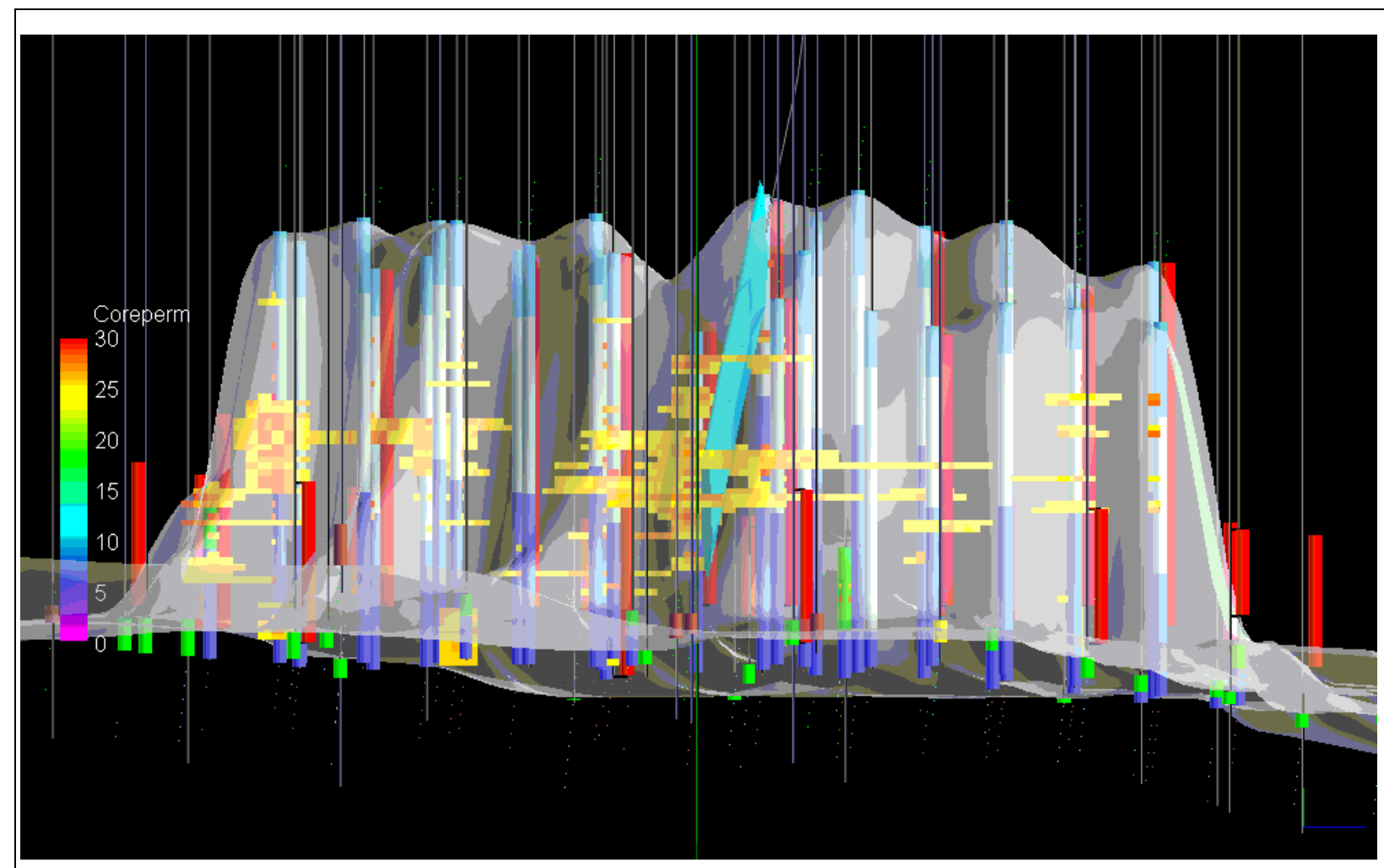

Figure 19. Belle River Mills "Glass Reef" presentation, showing permeability voxels $25 \mathrm{md}$ and greater (yellow and orange), stratigraphy (blues), cored intervals (red), and transparent top reef structure surface. The color scale on the left is core permeability in millidarcies from 0 to 30 . View is looking directly west. The cyan blue line in middle of reef is the deviated well drilled in 2000 (refer to Figure 6b). Vertical exaggeration is 10X. Voxel resolution is 115 feet in the $\mathrm{x}$ - and $\mathrm{y}$-directions and six feet in the $\mathrm{z}$-direction. 


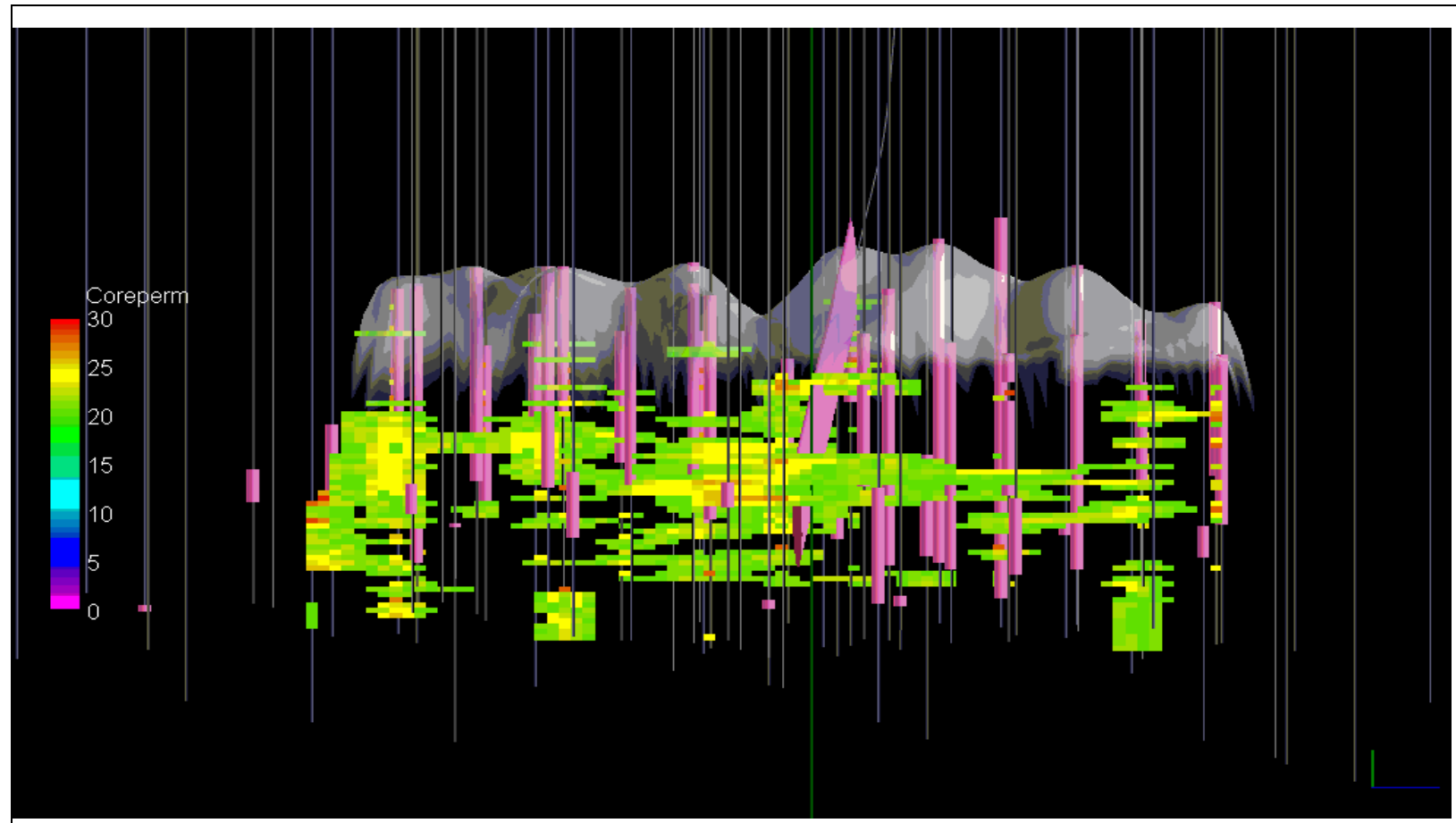

Figure 20. Belle River Mills 3D reef presentation, showing permeability voxels 20 md and greater (yellow and orange), original perforated intervals (purple), and transparent crestal reef structure surface. The color scale on the left is core permeability in millidarcies from 0 to 30 . View is looking directly west. Note the great thickness of perforations relative to the best permeability trends in the reservoir. The location of the perforations relative to the best permeability could impact primary, secondary, and enhanced recovery efforts as well as gas storage operations. Vertical exaggeration is $10 \mathrm{X}$. Voxel resolution is 115 feet in the $\mathrm{x}$ - and $\mathrm{y}$-directions and six feet in the z-direction. 


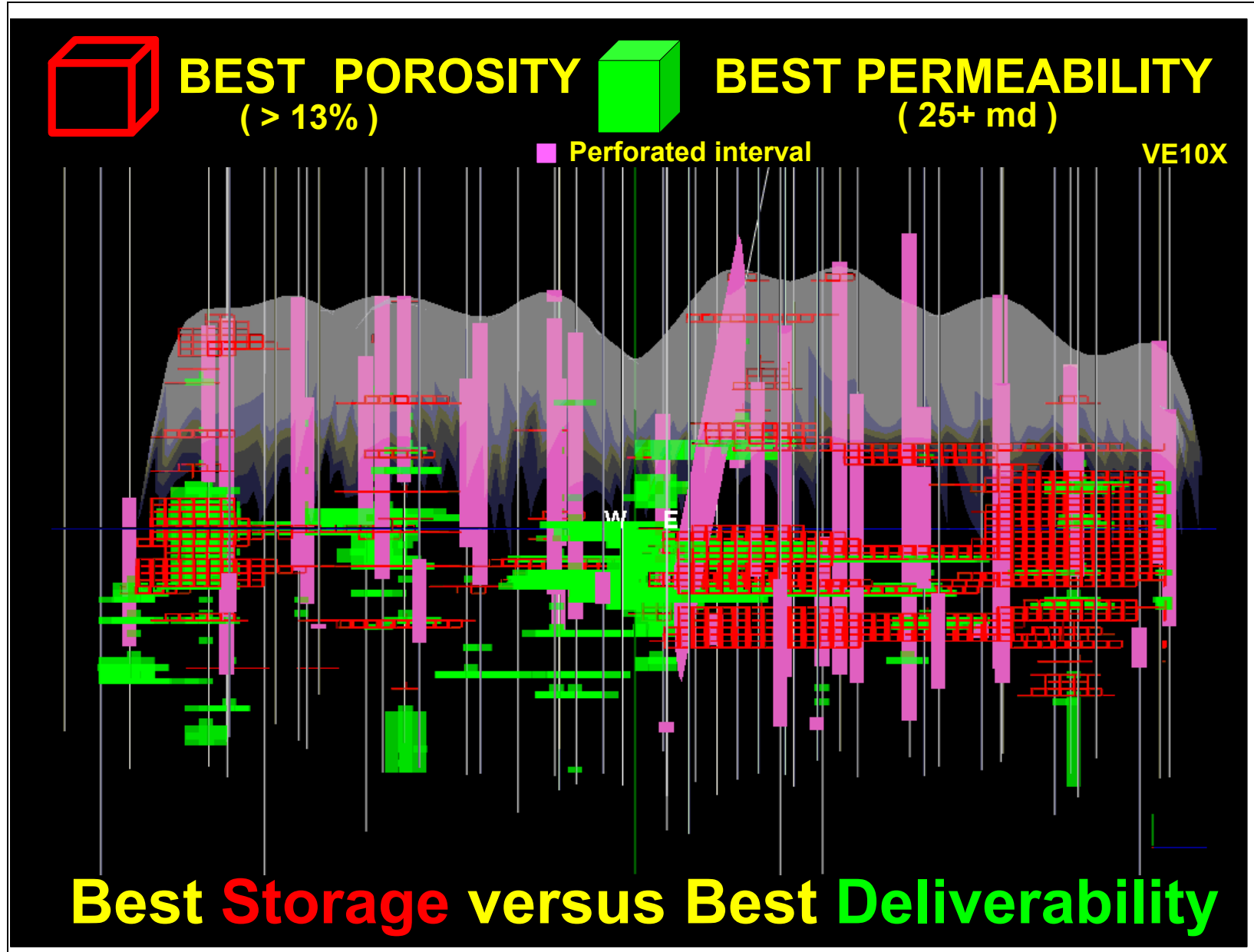

Figure 21. Belle River Mills 3D reef presentation, showing permeability voxels 25 md and greater (green), porosity voxels $13 \%$ and greater (red), original perforated intervals (purple), and transparent crestal reef structure surface. View is looking directly west. Note the location of the best permeability and porosity in relation to the perforated intervals. The best permeability is not necessarily coincident with the best porosity. 


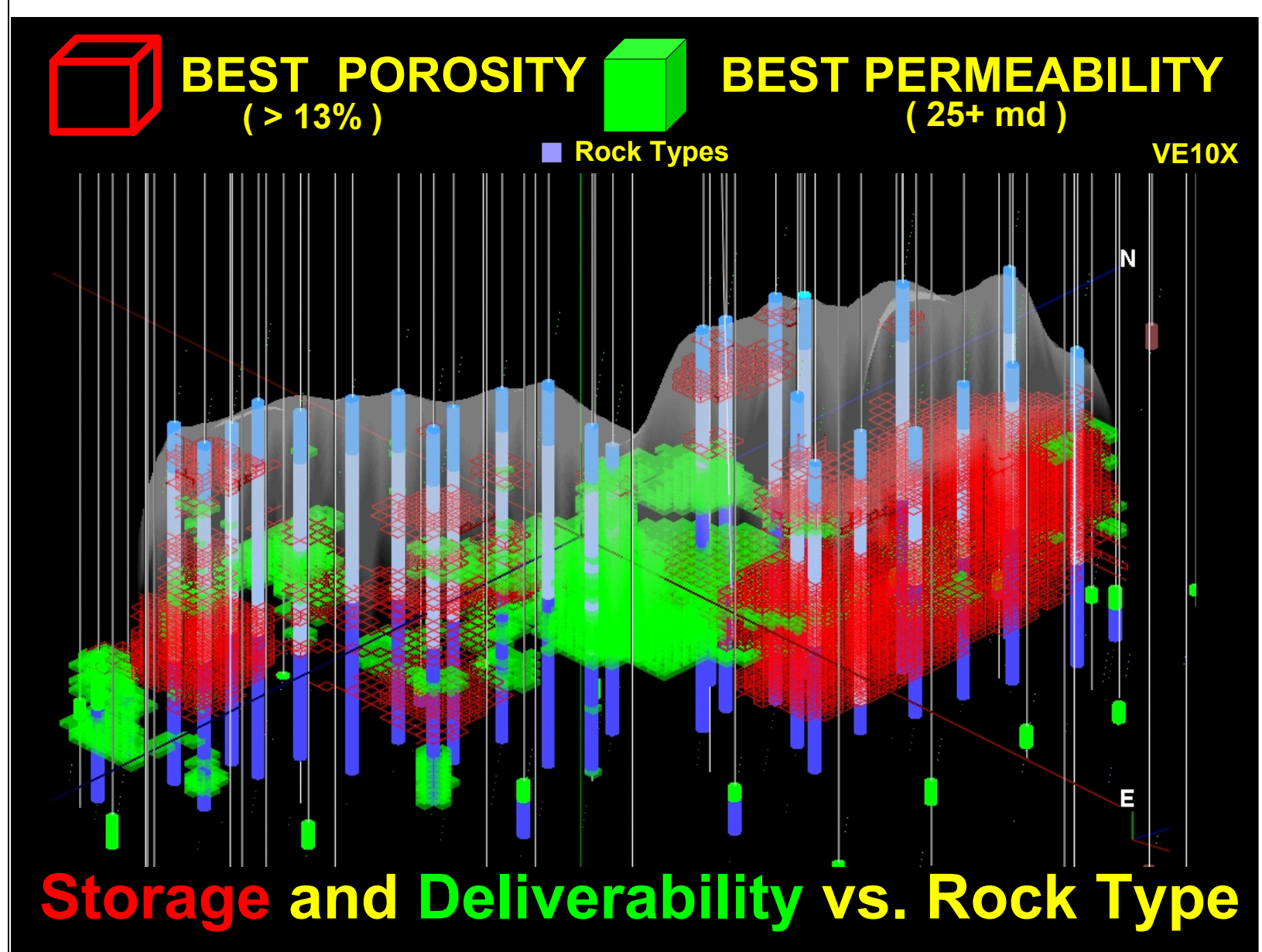

Figure 22. Belle River Mills 3D reef presentation, showing permeability voxels 25 md and greater (green), porosity voxels $13 \%$ and greater (red), rock types (blues and green), and transparent crestal reef structure surface. View is looking northwest. The best permeability and porosity is located in the upper wackestone and lower boundstone rock types. The stromatolite rock type generally has poor quality permeability and porosity. Storage and deliverability capacities of this gas storage reservoir could be optimized using this type of $3 \mathrm{D}$ visualization analysis. 


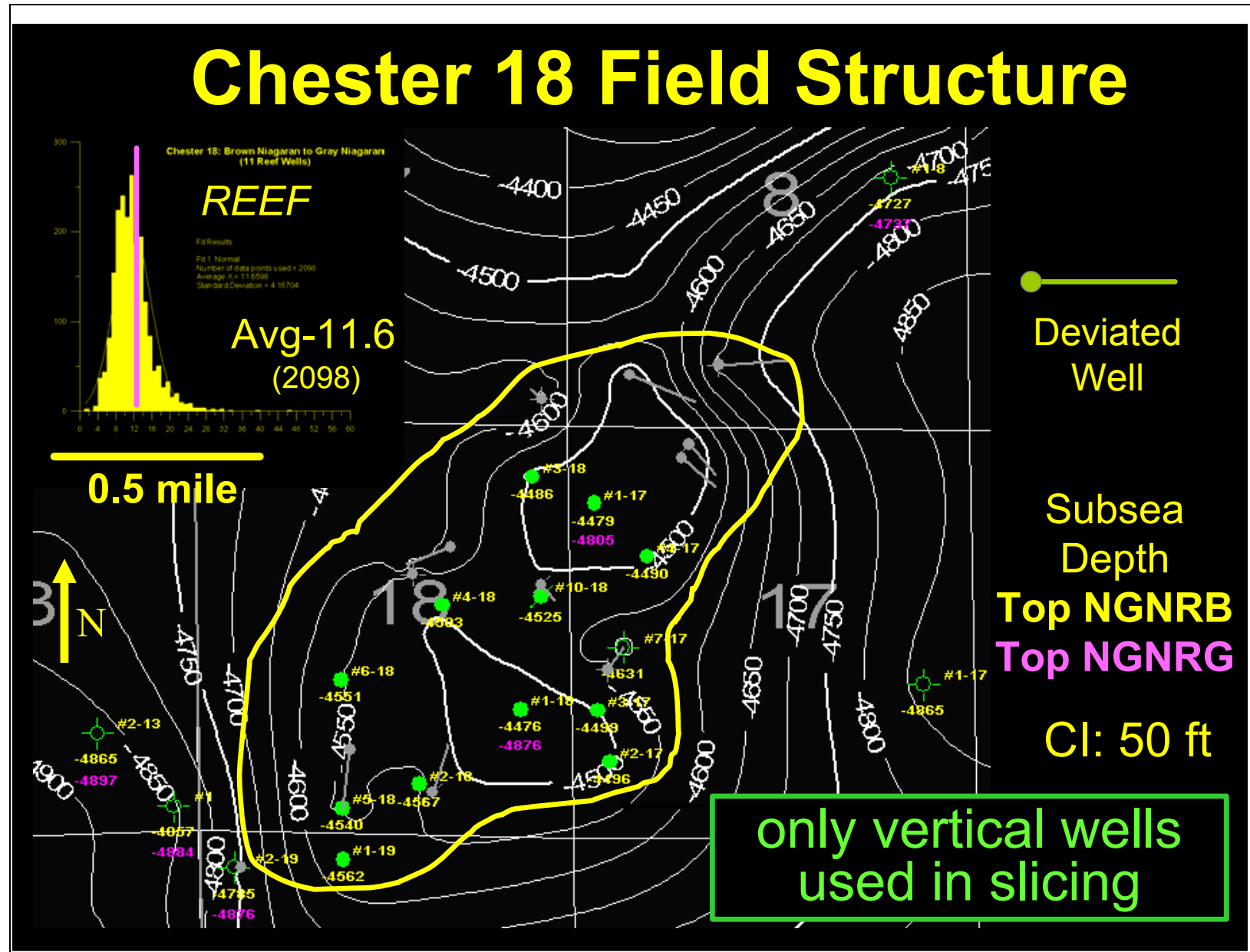

Figure 23. Structure map on the top of the Brown Niagaran (reservoir) for the Chester 18 Field, Otsego County, Michigan, 4 miles southwest of Dover 35 demonstration project (refer to Figure 1b). 


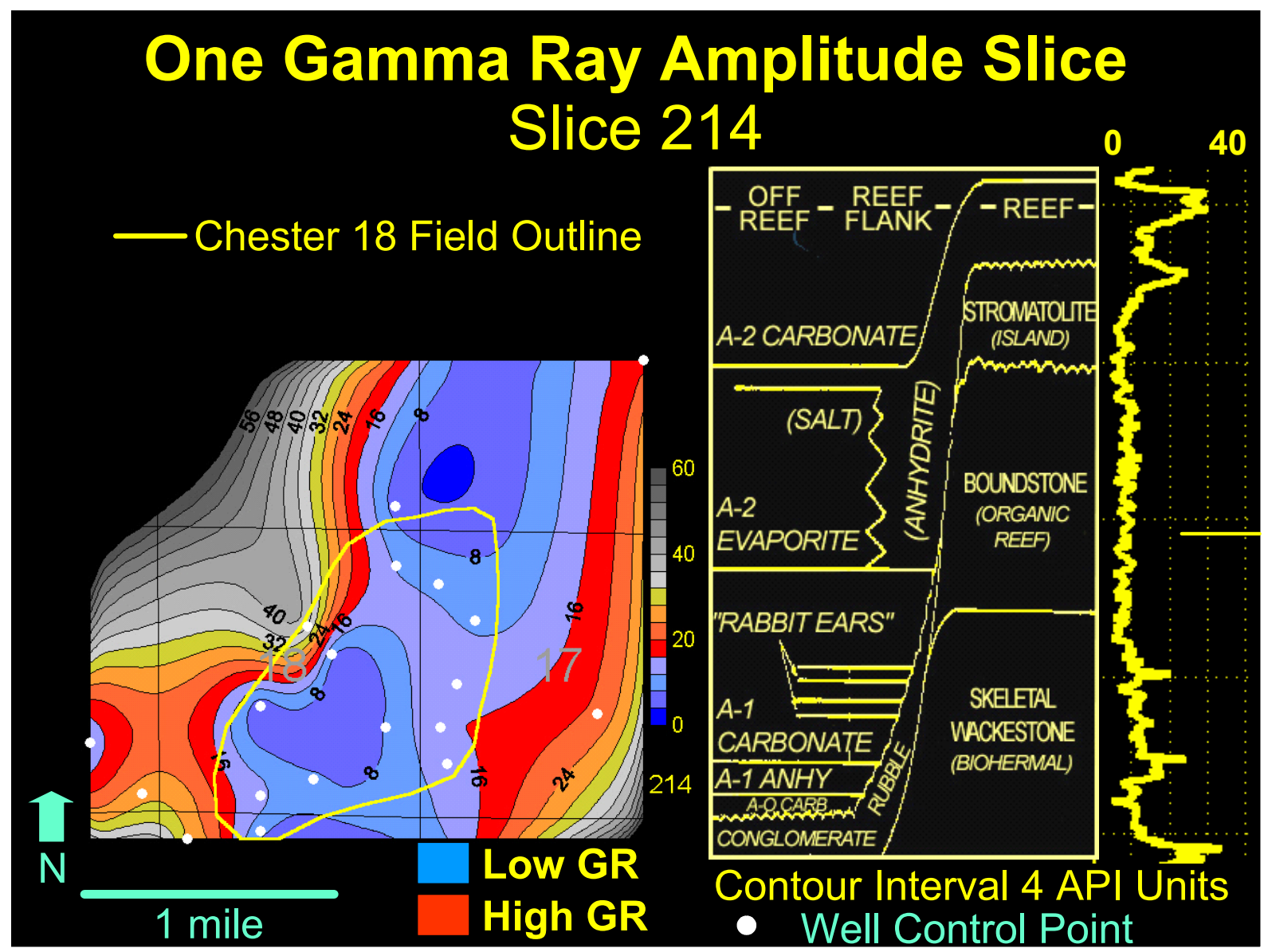

Figure 24. One gamma ray amplitude slice through Chester 18 Field (214 feet from reef base) displaying trends in the amplitude of the gamma ray curve. Slice contours indicate possibility of two depositional centers or two reefs that coalesced to form the Chester 18 reservoir. Pressure performance from the reservoir also indicates the possibility of two coalesced reefs. 


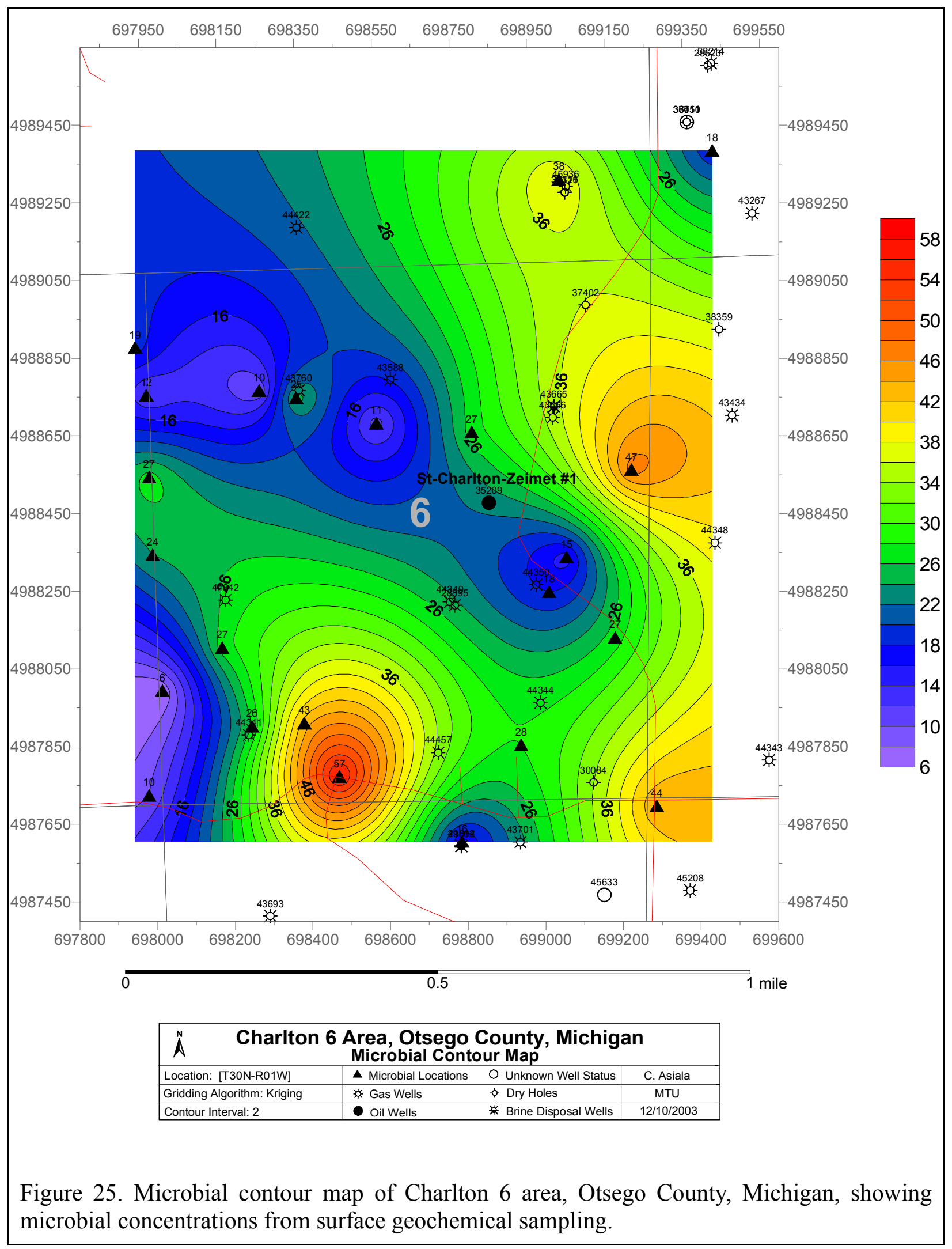

